\title{
Graphene saturable absorbers applications in fiber lasers
}

\author{
Xi Peng ${ }^{*}$ and Yixin Yan ${ }^{*}$
}

\begin{abstract}
Two-dimensional materials are widely used in a variety of fields, such as medical treatment, industrial preparation, machining, etc. In this review, we have made a detailed description of the development of fiber lasers as well as the evolution of two-dimensional materials, especially graphene. In addition, we describe the optical properties of graphene and its preparations, for instance, chemical exfoliatio, liquid phase exfoliation, electrochemical technique, chemical vapor deposition, supercritical fluid exfoliation, and thermal exfoliation. Meanwhile, we also summarized several types of graphene saturable absorbers like all fiber, D-shaped, and optical deposition. Furthermore, we summarize the optical applications of fiber lasers based on graphene. Finally, we also take a look at the future perspectives of graphene and discuss the future applications of graphene in the field of optics. It is note worth that future fiber lasers will use more heterostructures or gas-solid mixtures to prepare saturable absorbers.
\end{abstract}

Keywords: Two-dimensional materials, Graphene, Fiber lasers, Optical applications, Saturable absorber

\section{Introduction}

Fiber laser is a mature technology that has become an indispensable tool facilitating a wide range of science, medical diagnosis, biological sensor and industrial applications [1-7]. In the past decade, with the in-depth research of fiber lasers, the fiber lasers mixed with two-dimensional materials have been developed to further meet people's production and living needs, such as Er-doped fiber lasers, Yb-doped fiber lasers, Ho-doped fiber lasers, Tm-doped fiber lasers, $\mathrm{Pr}$-doped fiber laser, and $\mathrm{Nd}_{\mathrm{YOV}} \mathrm{YO}_{4}$-doped fiber lasers. Moreover, it should be pointed out that the recently proposed D-shaped fiber lasers [7-10], which has been widely accepted because its outstanding performance. As for fiber laser, there are two kinds of fiber lasers setup structure, including ring cavity and line cavity, while ring cavity is used more often. Advances in ultrafast fiber lasers have been applied as essential tools in a wide range of fields, such as laser physics, nanotechnology and medicine $[1,2,11]$.

\footnotetext{
*Correspondence: peng_xi678@126.com; yan_yixin999@126.com Heilongjiang Province Key Laboratory of Laser Spectroscopy Technology and Application, Harbin University of Science and Technology, Harbin 150080,
} China

More recently, an increasing number of attentions (SA) device attracts tremendous interest since it has the advantages of simple structure, low-cost, shorter achievbulse durations and high repetition rate.

In the field of lasers, there are two types of SA devices, use the nonlinear refractive index or birefringent properties to induce an intensity dependent nonlinear absorption, mimicking the response of real SAs. Take into this article. optical switch were demonstrated 4 years after the first laser emission reported by Maiman, where a colored glass filter and a reversibly bleachable dye were applied 
in Q-switched bulk lasers for short-pulse generation. Since then, SA technology has attracted a lot of attention from researchers, so it can be widely used in optical fiber lasers.

With the development of low-loss optical fiber, mode-locked lasers based on actively-doped fiber amplifiers emerged, including an early 1983 report of unstable mode-locking of a $\mathrm{Nd}: \mathrm{YOV}_{4}$-doped fiber fiber laser using a dye SA. However, until the semiconductor saturation absorption mirror (SESAM) was proposed in the early 1990s, generating stable modelocked pulses using passive mode-locked SA in optical fiber systems remained a challenge, SESAMs quickly became a highly successful technology for generating ultrafast mode-locked pulses and high-energy Qswitched emission from fiber lasers. Because of the optical properties of SESAMs, for example, narrow operating bandwidth, require costly fabrication and packing, and the relaxation speed is limited to picosecond timescales, so as to promote the development of new materials, including metals nanostructures, carbon nanotubes (CNTs) [12], topological insulators (TIs), transition metal oxides (TMO) [13], transition metal dichalcogenides (TMDs) [14-19], grapheme [20] and black phosphorous (BP). Whereas experimental research into the photonics properties of such material remains at an early stage, it has offered new opportunities for photonic and optoelectronic applications in compact ultrafast light sources.

More recently, graphene has triggered rapid growing interests in both academic research and potential applications since its remarkable properties. Few layer graphene presents layer-count-dependent properties, which is a typical feature for $2 \mathrm{D}$ nanomaterials. For instance, it has been shown that we make different saturable absorbers by changing the number of graphene layers, such as from 9 to 28 layers, then applying them to different fiber laser will produce different light source outputs. Nowadays, there are several types of graphene saturable absorbers, such as Dshaped, all-fiber lasers, optical deposition grapheme $\mathrm{SA}$, but the graphene-based D-shaped saturable absorber technology has been demonstrated to produce shorter pulse-high repetitive frequency light source output, with practical advantages of simple structure, low cost and superior performance, which prompts the extensive investigation of this material, enabling its fabrication into versatile photonic and optoelectronic devices for desirable applications.

In this review, we summarized the current development situation of graphene based photonics devices, including their fabrication and integration process. Besides, we also summarized the structural types of graphene saturated absorbers and applications as SA devices for graphene-based fiber lasers. Based on these advances, a conclusion and outlook of new potential opportunities of graphene-based devices in future optoelectronic and photonic technologies are highlighted.

\section{Material optical properties and preparations Graphene optical properties}

Graphene is the name given to a fiber at monolayer of carbon atoms tightly packed into a two-dimensional (2D) honeycomb lattice [21], and is a basic building block for graphitic materials of all other dimensionalities, as shown in the inset of Fig. 1. Due to its flexible structure can be formed into many shapes, so it is widely used in different fields of material science for developing nanocomposites, sensors, supercapacitors, hydrogen storage and optoelectronic devices [23-43]. In this regard, it is important to highlight that graphene has a variety of properties, such as electronic properties, mechanical properties, optical properties and thermal properties. The function of graphene in burgeoning applications is based on one or more fundamental properties [23, 44-50].

Compared with other two-dimensional materials, saturated absorption appliances made of graphene have the advantages of low cost, good stability and environmental protection, especially the excellent performance of optical properties. As shown in Fig. 2, this constant transparency has been experimentally observed for graphene in the visible range and the transmittance linearly decreases with the number of layers for n-layer graphene.

Since its unique optical properties, for example, ultrabroad tuning range, graphene may be widely used as a saturable absorber for all types of fiber lasers [21]. Other outstanding optical properties, such as very low saturable absorption threshold level and high modulation depth, provide new possibilities in terms of ultrafast mode-locked fiber lasers development [52]. It is the basic unit in order to build other dimensional carbon materials (such as zero-dimensional fullerenes, onedimensional carbon nanotubes, and three-dimensional graphite). In 2009, Bao et al. first confirmed the use of atomic-level graphene as a saturable absorber for modelocking of Er-doped fiber lasers [53]. Most of the research has focused on the optimization of graphene mode-locking and Q-switching performance in wavebands as saturable absorbers [15, 16, 32, 54, 55].

The Raman spectra of as-produced graphene samples are shown in Fig. 3. The monolayer and 3-layer graphene samples are plotted in black solid line and red short dash line, respectively. From the two curves, we can see three typical peaks of graphene around $1340 \mathrm{~cm}, 1590 \mathrm{~cm}$ and $2660 \mathrm{~cm}$, which represent D 


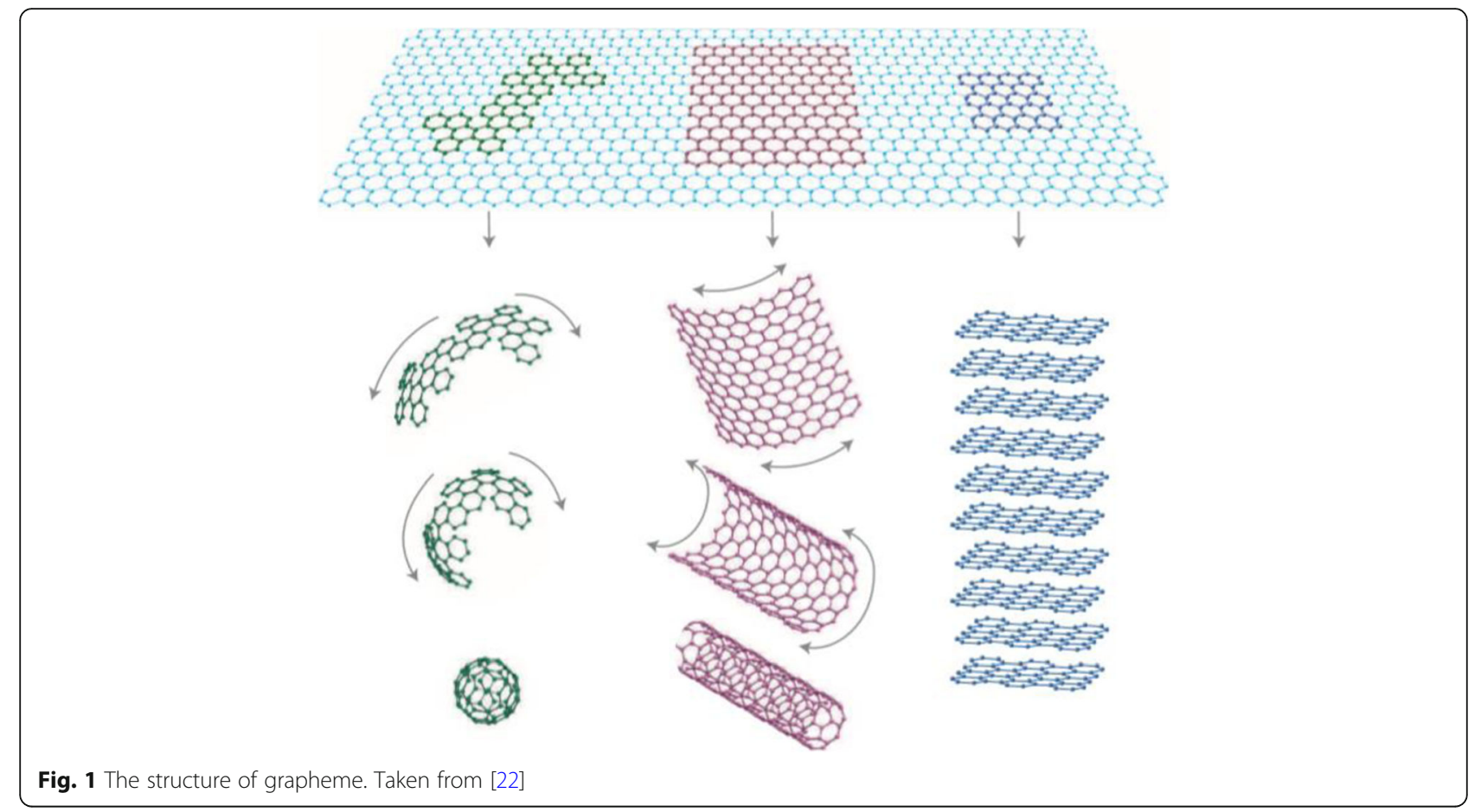

band, G band and 2D band [34]. The much sharper and higher 2D band peak shows the characterization of monolayer graphene and that of 3-layer graphene is lower. The intensity ratios of D and $G$ bands are very low, which indicate the high quality of the two graphene samples. In addition, this free-carrier response of graphene supports the 2D plasmon mode, which exhibits unusually strong confinement and a distinctive dependence on carrier concentration. The ability to control broadband graphene absorption and plasmon excitation through electrostatic gating has enabled many electro-optic modulator designs based on graphene which function at the terahertz to visible wavelengths [57].

The mechanical properties of monolayer graphene including Young's modulus and fracture strength have

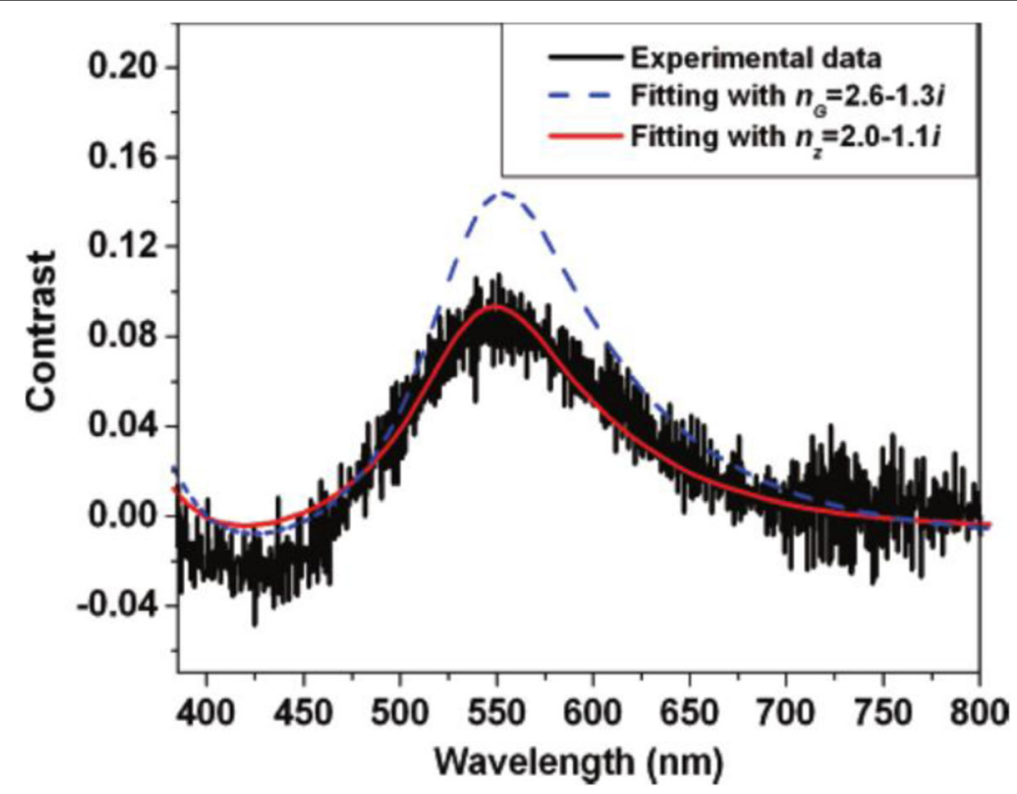

Fig. 2 Graphene optical properties. Taken from [51] 

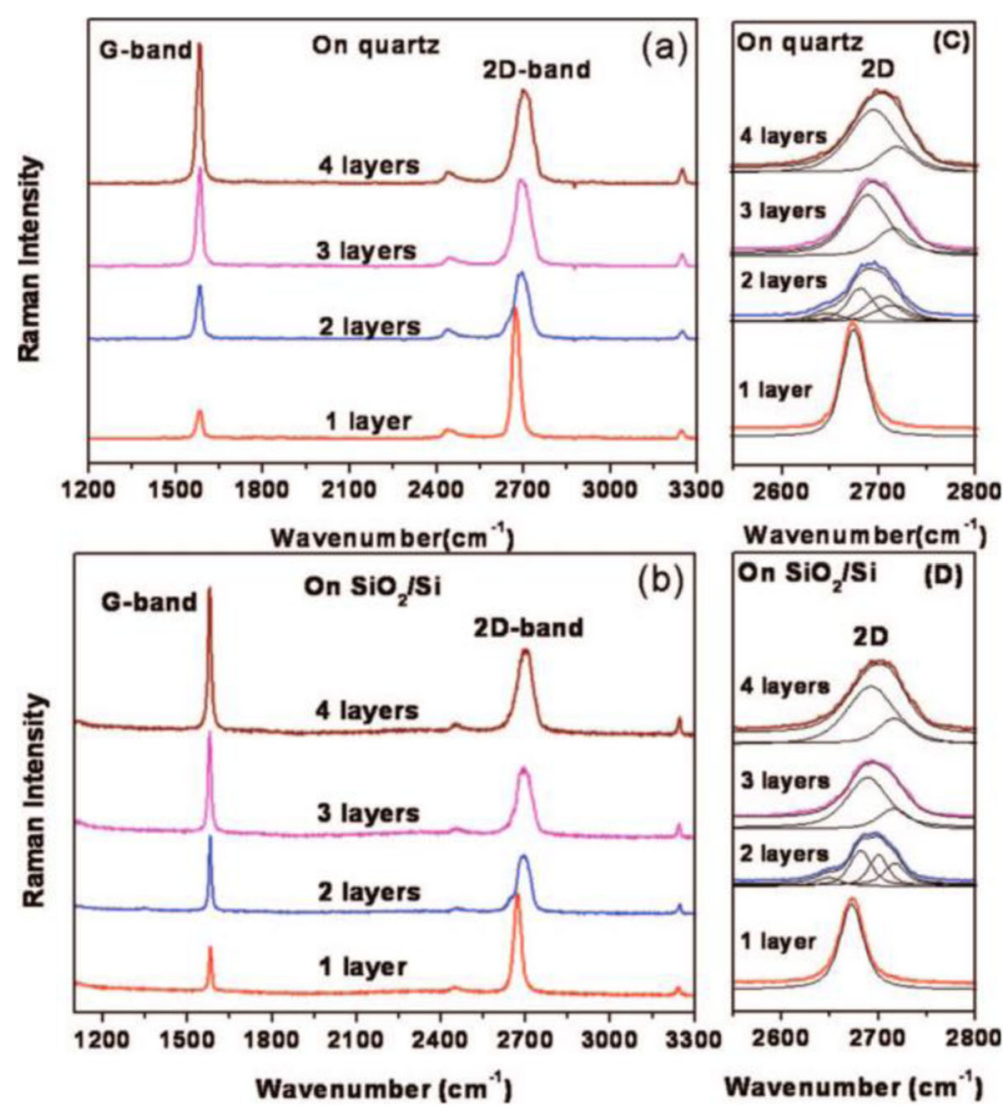

Wavenumber( $\left.\mathrm{cm}^{-1}\right)$

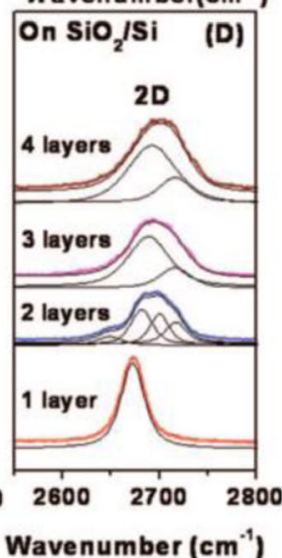

Wavenumber (cm

Fig. 3 The Raman spectra of monolayer, bilayer, three layers, and four layers grapheme on quartz (a) and SiO2 (300 nm)/Si substrate (b). The enlarged 2D-band regions with curve fit are also shown in panels $\mathrm{c}$ and $\mathrm{d}$. Taken from [56]
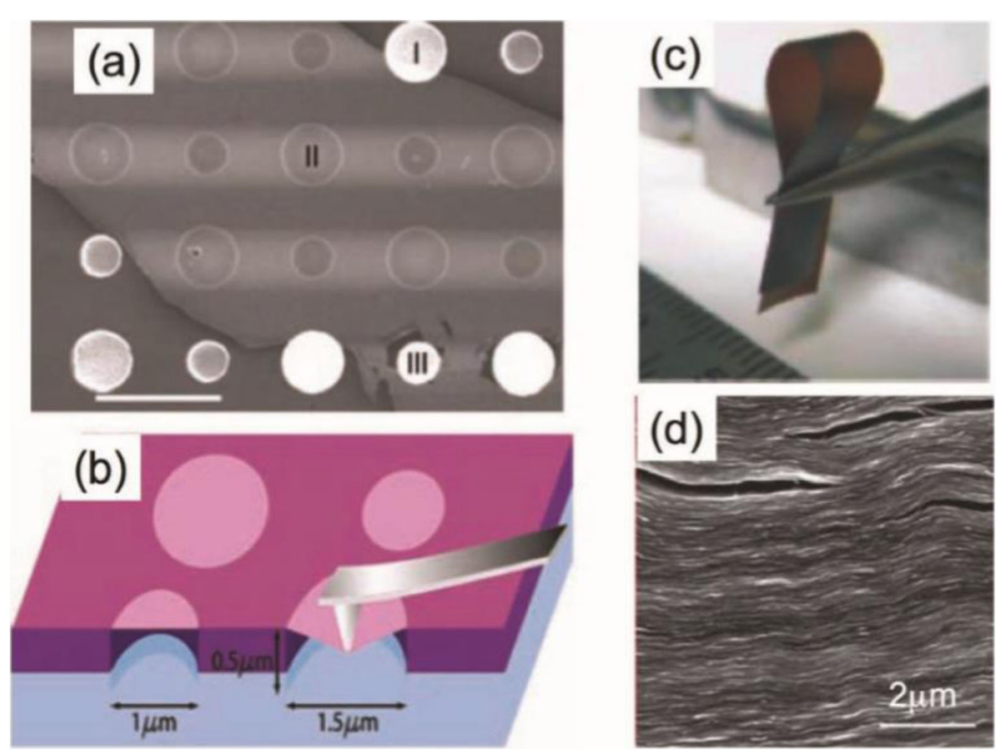

Fig. 4 Mechanical properties of grapheme. a Scanning electron microscopy (SEM) image of a graphene flake spanning an array of circular holes (scale bar, $3 \mu \mathrm{m}$ ) and $\mathbf{b}$ Schematic illustration of nanoindentation on membranes; $\mathbf{c}$ and $\mathbf{d}$ show graphene oxide paper and its cross-section in SEM. Reproduced with permission from ( $\mathbf{a}$ and $\mathbf{b}$ ) and (c and $\mathbf{d})$. Copyright: 2008 American Association for the Advancement of Science (a and $\mathbf{b})$ and 2007 Nature Publishing Group (c and d). Taken from [58] 


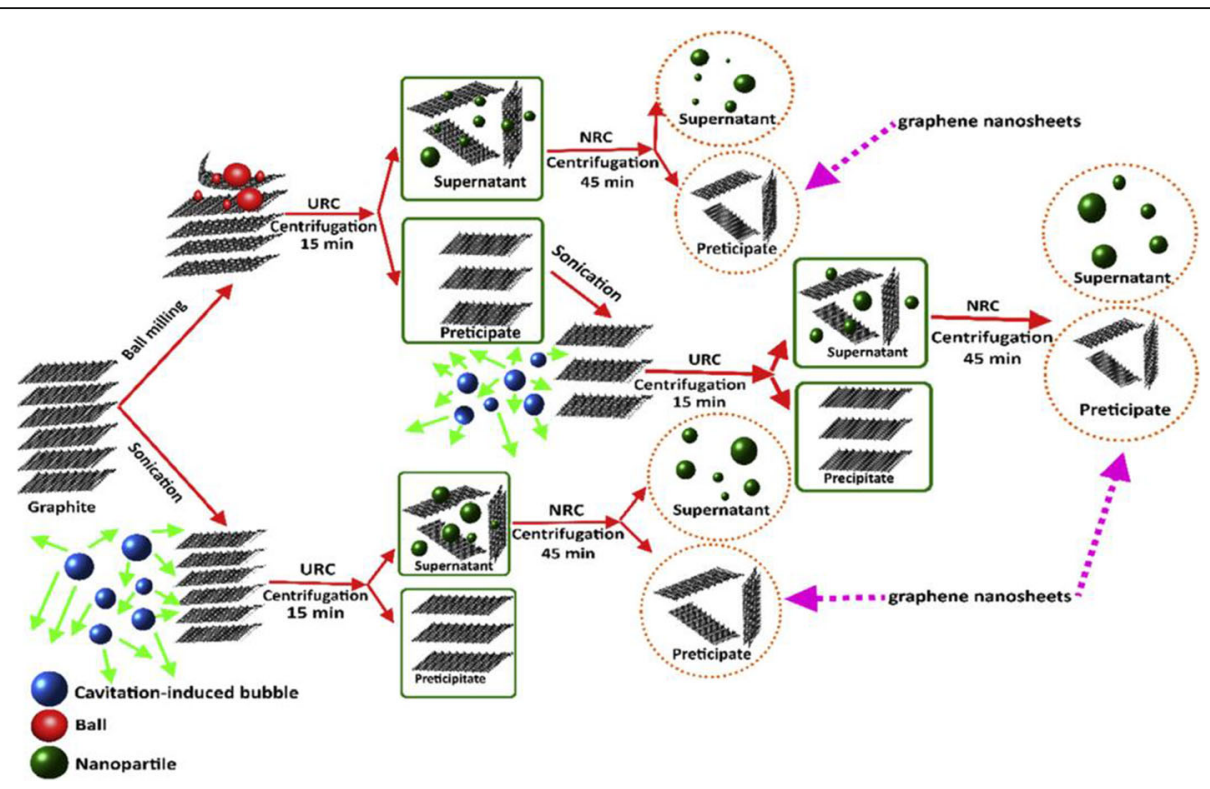

Fig. 5 Mechanism of graphite exfoliation through two methods and a combination of both in order to increase the yield and reuse of all the products of milling. Taken from [60]

been investigated by numerical simulations such as molecular dynamics. The Young's modulus of few-layer graphene was experimentally investigated with forcedisplacement measurements by atomic force microscopy (AFM) on a strip of graphene suspended over trenches. Recently, the elastic properties and intrinsic breaking strength of free-standing monolayer graphene were measured by nanoindentation using AFM shown in Fig. 4.

Graphene has high electron carrier mobility, but it is a zero band gap semimetal. When graphene is used in the $\mathrm{SiO}_{2}$ sub-strate to manufacture a transistor, performance of grapheme decreases due to roughness of the surface, charged surface and $\mathrm{SiO}_{2}$ surface optical phonons. Therefore, graphene-based heterostructures are preferred instead of using pure graphene especially in transistor applications.

\section{Material preparations}

2D materials used in the preparation of saturated absorber, such as disulfide, black phosphorus, graphene, transition metal disulfide. In the case of graphene, various methods have been used to prepare graphene including chemical exfoliation [59], liquid phase exfoliation (LPE) [13, 60], electrochemical technique [61-63], chemical vapor deposition (CVD) [64, 65], supercritical fluid exfoliation [66-69], thermal exfoliation [70], etc. However, liquid phase exfoliation (LPE) is one of the most important methods among top down graphene production techniques. This procedure includes direct exfoliation of graphite to three graphene layers by shear forces through ultra sonication, which is a simple, cheap, and environmental friendly approach without using hazardous materials such as strong acids and hydrazine derivatives. The schematic representation of the liquid-phase exfoliation is depicted in Fig. 5.

In this section, we will focus on the CVD method [19, $55,71-77]$, because this method is widely used in all kinds of experiments. Graphene saturable absorbers may be formed due to chemical methods, such as dispersing graphite sheets in different solvents (polyvinyl alcoholPVA, dimethyl formamide-DMF), CVD on $\mathrm{Ni} / \mathrm{Si}$

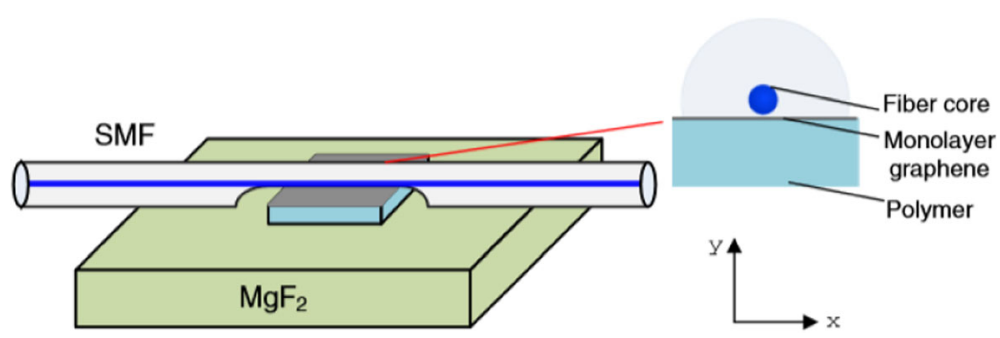

Fig. 6 Schematic structure of the graphene-based SA; the right schematic diagram is the cross section. Taken from [80] 


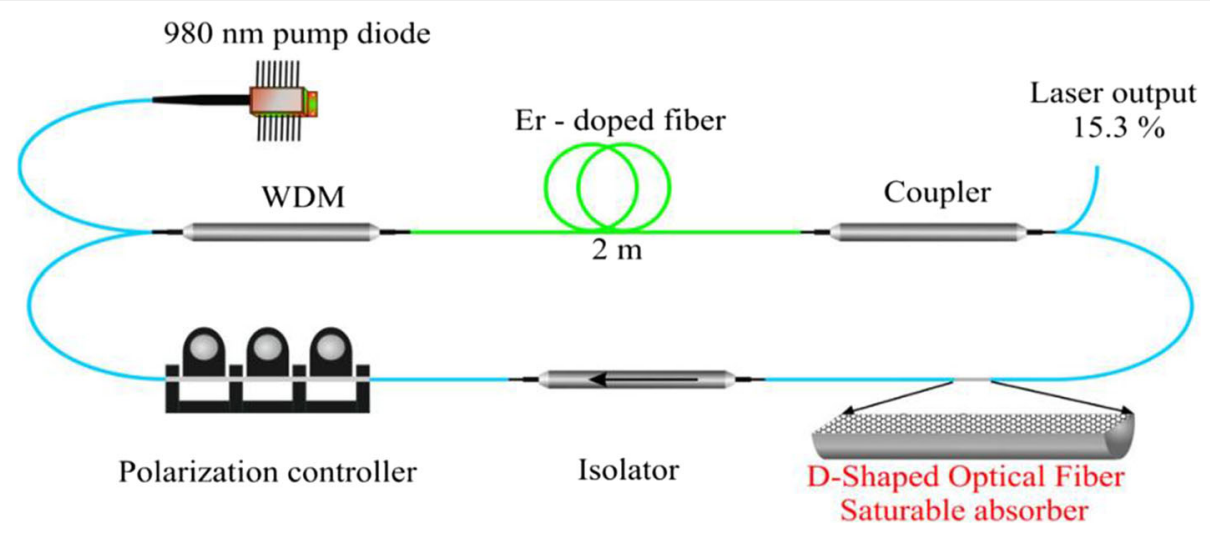

Fig. 7 Passively mode locked by graphene saturable absorber on D-shaped optical fiber. Taken from [81]

substrates [38], or epitaxial growth on $\mathrm{SiC}$ substrates. The another efficient method is based on mechanical exfoliation of graphene from pure graphite [78], most likely highly ordered pyrolytic graphite (HOPG). By employing CVD method, samples of graphene were prepared as follows: firstly, monolayer and three-layer graphene thin films were grown on $\mathrm{Cu}$ foils separately, then we use ammonium persulfate to etch the copper. After thorough rinsing in the distilled water, the graphene samples were floating on the water. Finally, the samples were fished by quartz substrate and dried in nitrogen gas [38]. Nowadays, an increasing number of research using Cryogenic liquid stripping in the laboratory, which low cost, easy to make and stable performance.

\section{Graphene-based saturable absorbers D-shaped}

These D-shaped fiber laser with this structure is mainly using ring cavity. We present graphene saturable absorbers on D-shaped optical fiber for fast and ultrashort pulse generation [79]. Furthermore, the materials are obtained by CVD, liquid-phase exfoliation or mechanical exfoliation of graphite. Figure 6 illustrates the schematic structure of the graphene-based SA. The monolayer graphene film is directly synthesized by the CVD method on polycrystalline $\mathrm{Cu}$ substrate [38]. The polymer clad resin is uniformly adhered to the graphene film on a $\mathrm{Cu}$ substrate without an air bubble in it, and is then cured by ultraviolet (UV) light. After $24 \mathrm{~h}$, the polymer/graphene $/ \mathrm{Cu}$ layers are soaked with $0.05 \mathrm{mg} / \mathrm{mlFeCl}_{3}$ solution to remove the $\mathrm{Cu}$ layer. Then the ferric icon is washed away from polymer or graphene layers using distilled water. The length of the graphene is $10 \mathrm{~mm}$. Finally, after cleaning the polished surface of the D-shaped fiber with $99.5 \%$ propyl alcohol, the polymersupported monolayer graphene film is transferred onto the flat surface of the D-shaped fiber for interaction with the evanescent field. Such a structure is used as the graphene-based SA in fiber laser system. In addition, it should be noted that the thickness of D-shaped fiber should be between $67 \mu \mathrm{m}$ (on top of fiber core) and $77 \mu \mathrm{m}$, in order to obtain a low loss and strong evanescent field simultaneously. Considering the interaction length of $10 \mathrm{~mm}$ of graphene, the $72 \mu \mathrm{m}$ thickness of D-shaped fiber is appropriate to structure.

The experimental setup of the Er-doped fiber laser with total length of $15.4 \mathrm{~m}$ [80], as shown in the Fig. 7. It consists of a $2 \mathrm{~m}$ length Er-doped fiber with absorption coefficient $-33.8 \mathrm{~dB} / \mathrm{m}$ and dispersion coefficient of $-57.0 \mathrm{ps} / \mathrm{nm} / \mathrm{km}$ at $1550 \mathrm{~nm}$, a $980 \mathrm{~nm}$ semiconductor pump laser coupled in co-propagating configuration
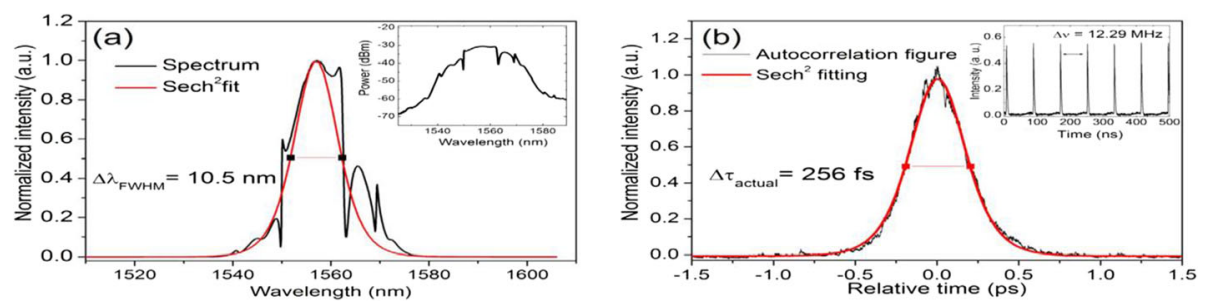

Fig. 8 The experimental results obtained from the D-shaped fiber lasers on passively mode-locking. a Output linear spectrum (inset - log scale spectrum) and $\mathbf{b}$ autocorrelation trace (inset - cavity fundamental repetition rate). Taken from [82] 
Table 1 Typical properties of D-shaped fiber lasers

\begin{tabular}{|c|c|c|c|c|c|}
\hline Average output power & Pulse energy & Center wavelength & Pulse duration & Repetition frequency & Ref \\
\hline $15.78 \mathrm{~mW}$ & - & $1559.42 \mathrm{~nm}$ & $1.93 \mu \mathrm{s}$ & $73.96 \mathrm{KHz}$ & [79] \\
\hline $20 \mathrm{~mW}$ & - & $1560 \mathrm{~nm}$ & $200 \mathrm{fs}$ & $14.53 \mathrm{MHz}$ & [83] \\
\hline $40 \mathrm{~mW}$ & $\ln J$ & 1563 nm & $713 \mathrm{fs}$ & $11.53 \mathrm{MHz}$ & {$[80]$} \\
\hline $20 \mathrm{~mW}$ & - & $1560 \mathrm{~nm}$ & $256 \mathrm{fs}$ & $12.29 \mathrm{MHz}$ & [84] \\
\hline $0.2 \mathrm{~mW}$ & 83p」 & $1565 \mathrm{~nm}$ & $310 \mathrm{fs}$ & $13.52 \mathrm{MHz}$ & [85] \\
\hline $0.2 \mathrm{~mW}$ & 83pJ & $1567 \mathrm{~nm}$ & $220 \mathrm{fs}$ & $15.70 \mathrm{MHz}$ & [86] \\
\hline $16 \mathrm{~mW}$ & - & $1597.53 \mathrm{~nm}$ & $1.42 \mathrm{ps}$ & $2.08 \mathrm{GHz}$ & {$[87]$} \\
\hline $1.51 \mathrm{~mW}$ & $7.25 \mathrm{~nJ}$ & $1560.45 \mathrm{~nm}$ & $1.05 \mathrm{ps}$ & $11.19 \mathrm{MHz}$ & [88] \\
\hline $66.44 \mathrm{~mW}$ & - & $1544.02 \mathrm{~nm}$ & $1.17 \mathrm{ps}$ & $16.79 \mathrm{MHz}$ & [89] \\
\hline $80 \mathrm{~mW}$ & - & $1558.8 \mathrm{~nm}$ & $1.38 \mathrm{ps}$ & $8.3 \mathrm{MHz}$ & [90] \\
\hline $18.22 \mathrm{~mW}$ & $1.44 n J$ & $1567.29 \mathrm{~nm}$ & $1.38 \mathrm{~ns}$ & $12.66 \mathrm{MHz}$ & [91] \\
\hline $253 \mathrm{~mW}$ & $3.3 n J$ & $1558.7 \mathrm{~nm}$ & $4.42 \mathrm{~ns}$ & $1.04 \mathrm{MHz}$ & [92] \\
\hline $23.5 \mathrm{~mW}$ & $1.97 n\rfloor$ & $1550 \mathrm{~nm}$ & 1.04 ps & $11.9 \mathrm{MHz}$ & [93] \\
\hline $54 \mathrm{~mW}$ & $2.55 \mathrm{~nJ}$ & $1560 \mathrm{~nm}$ & $530 \mathrm{fs}$ & $27 \mathrm{MHz}$ & [94] \\
\hline $5.11 \mathrm{~mW}$ & - & $1557 \mathrm{~nm}$ & $1.21 \mathrm{ps}$ & $15.76 \mathrm{MHz}$ & {$[3]$} \\
\hline $22.4 \mathrm{~mW}$ & - & $1557.5 \mathrm{~nm}$ & $621.5 \mathrm{fs}$ & $22.74 \mathrm{MHz}$ & [95] \\
\hline
\end{tabular}

through a 980/1550 nm WDM, an isolator with $50 \mathrm{~dB}$ isolation and $0.07 \mathrm{~dB}$ loss at $1550 \mathrm{~nm}$, a polarization controller and an output coupler of $15.3 \%$. The cavity average dispersion was $6 \mathrm{ps} / \mathrm{km} / \mathrm{nm}$ and the accumulated dispersion was $100 \mathrm{fs} / \mathrm{nm}$. The experimental results obtained from the D-shaped fiber lasers on passively mode-locking is shown in Fig. 8, where the central wavelength, pulse duration and repetition rate are $1565 \mathrm{~nm}, 256 \mathrm{fs}$ and $12.29 \mathrm{MHz}$, respectively [81] (Table 1).

In a word, the fiber laser with D-shaped saturation absorber has the advantages of high output pulse frequency, high large output power and short pulse duration. Besides, the laser structure is simple, low cost and easy to manufacture. In the future, due to better optical properties, it is will be more likely to attract

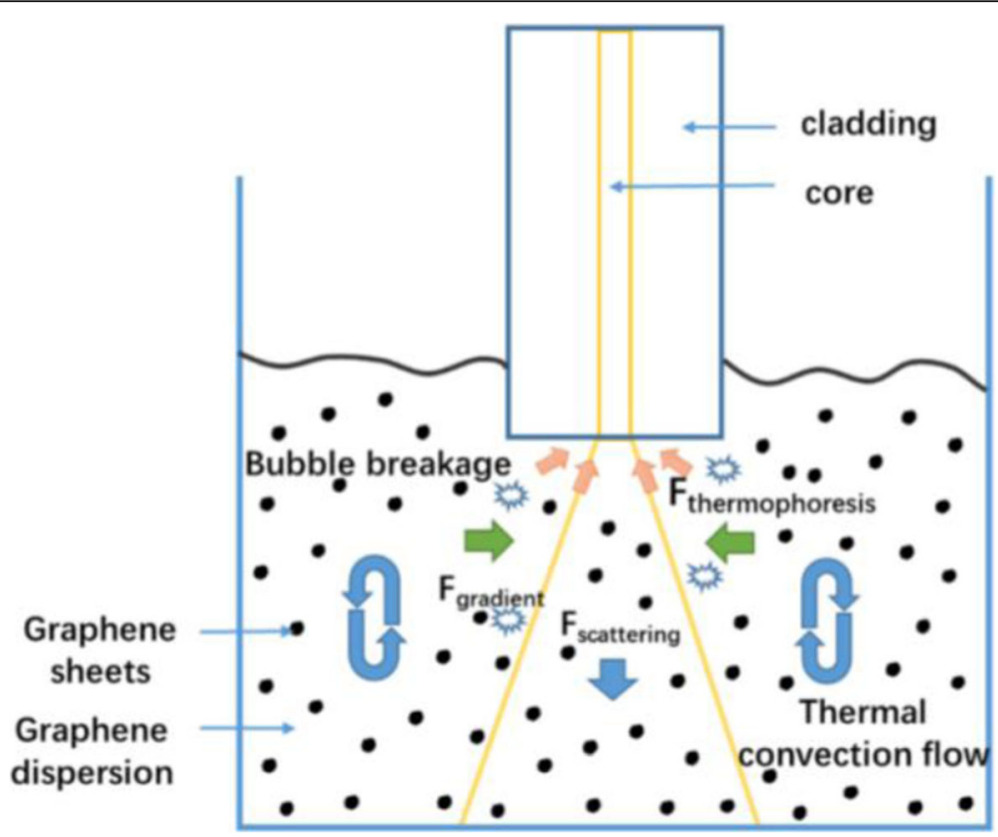

Fig. 9 Mechanism of the optical deposition of graphene. Taken from [74] 


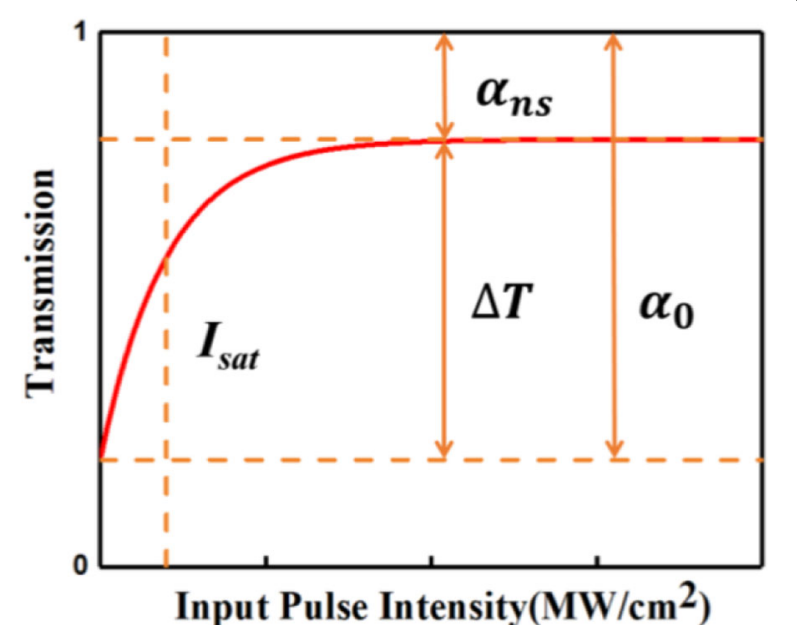

Fig. 10 Transmission curve for a saturable absorber. Taken from [74]

the attention of researchers and be widely used in a variety of fields [79-81, 83-86, 96].

\section{All fiber}

At present, graphene saturated absorbers in all-fiber form are widely used in fiber lasers. In this review, we summarize various of the most common all-fiber lasers in recent years, for instance, Er-doped [97], Yb-doped [98],Ho-doped [94], Tm-doped [11], Pr-doped [49, 75, 77] and Nd:YVO 4 -doped [39]. Meanwhile, the Er-doped fiber lasers are used in a growing number of academic research and optical field, due to its many great optical properties, such as light absorption, high repetition frequency as well as the pulse duration is short. However, with the rapid development of fiber lasers, an increasing amount of $2 \mathrm{D}$ materials are used in the research of ultrafast lasers.

By analyzing these common fiber lasers, the preparation methods of graphene saturated absorbers are various, including CVD, ME and LPE. However, from the perspective of production difficulty, performance stability and production cost, it can be concluded that the graphene saturated absorber made by CVD method has good stability, low cost and simply make.

Overall, the central frequency of all-fiber laser is concentrated at about $1.5 \mathrm{um}$, and it can also generate a light source with a central frequency of 2 um. Most all-fiber lasers produce light sources of $\mathrm{MHz}$ repetition frequency and pulse duration from femtosecond to microsecond. In the future laser research field, there will be a new type of optical fiber laser composed of all-fiber and various noble gases with good optical properties.

\section{Optical deposition}

To place graphene onto fiber end to fabricate graphene saturable absorber (GSA), various methods have been proposed, for instance, chemical vapor deposition, polymer nanocomposite and optical deposition [47, 48, 74, 99-101]. Among the methods mentioned above, what's more, optically driven deposition is the simplest and effective way to deposit graphene onto the fiber end. The optical deposition method was first proposed and performed to deposit carbon nanotubes in 2007. Subsequently, it was also shown that graphene could be optically deposited on the fiber end as a SA. However, more detailed information about the factors that influence the process of optical deposition of graphene was not provided in early investigations.

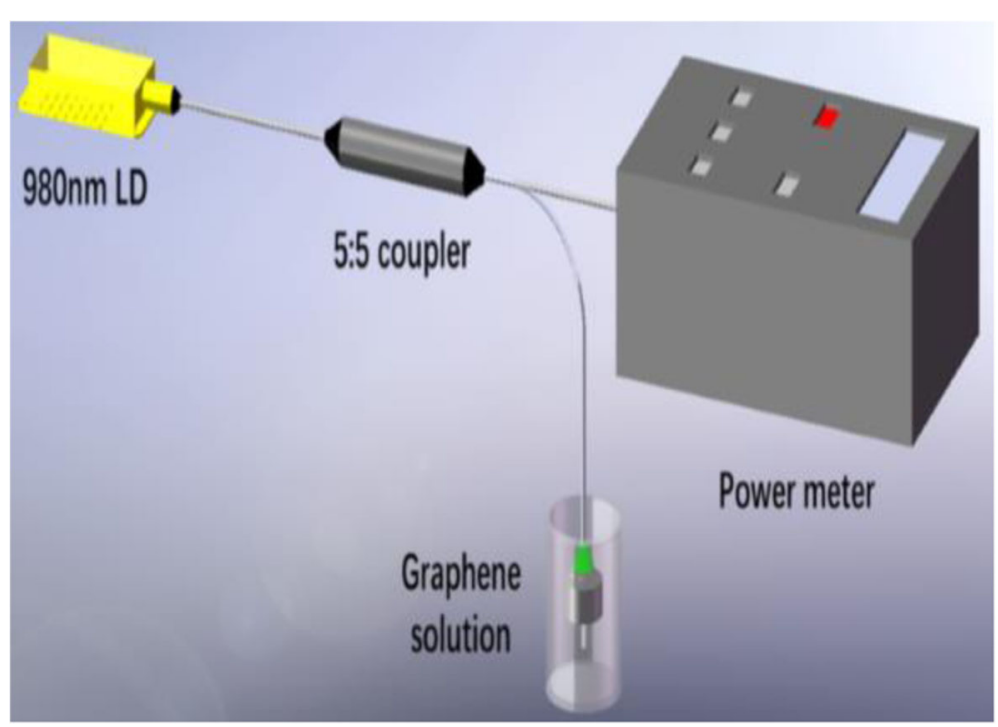

Fig. 11 Experimental setup for graphene optical deposition. Taken from [74] 
Table 2 Typical properties of mode-locked Er-doped fiber lasers

\begin{tabular}{|c|c|c|c|c|c|c|}
\hline Fabrication method & Average output power & Pulse energy & Center wavelength & Pulse duration & Repetition frequency & Ref \\
\hline \multirow[t]{2}{*}{ CVD } & \multirow[t]{2}{*}{$1.9 \mathrm{~mW}$} & \multirow[t]{2}{*}{ 33p」 } & $1564 \mathrm{~nm}$ & $315 \mathrm{fs}$ & $57.96 \mathrm{MHz}$ & [105] \\
\hline & & & $1567 \mathrm{~nm}$ & $844 \mathrm{fs}$ & $16.34 \mathrm{MHz}$ & [106] \\
\hline ME & $30 \mathrm{~mW}$ & $17.7 p J$ & 1567 nm & $647 / 728$ fs & 294/800 MHz & [107] \\
\hline CVD & $18 \mathrm{~mW}$ & $0.7 \mathrm{~nJ}$ & $2784.5 \mathrm{~nm}$ & $42 \mathrm{ps}$ & $25.4 \mathrm{MHz}$ & [108] \\
\hline ODD & $33 \mathrm{~mW}$ & $82.61 n J$ & $1565.6 \mathrm{~nm}$ & $1.8 \mathrm{ps}$ & $6.9 \mathrm{MHz}$ & [109] \\
\hline CVD & $80 \mathrm{~mW}$ & - & $1550 \mathrm{~nm}$ & $6.5 \mathrm{ps}$ & $2.3 \mathrm{THz}$ & [103] \\
\hline CVD & $130 \mathrm{~mW}$ & $7.3 n 」$ & $1576.3 \mathrm{~nm}$ & $415 \mathrm{fs}$ & $6.84 \mathrm{MHz}$ & {$[40]$} \\
\hline CE & $5 \mathrm{~W}$ & $3 n J$ & $1590 \mathrm{~nm}$ & $700 \mathrm{fs}$ & $6.95 \mathrm{MHz}$ & [110] \\
\hline CE & $27 \mathrm{~mW}$ & - & $1531.3 \mathrm{~nm}$ & $1.21 \mathrm{ps}$ & $1.888847 \mathrm{MHz}$ & [111] \\
\hline CVD & $3.85 \mathrm{~mW}$ & $0.26 n J$ & $1562.76 \mathrm{~nm}$ & $500 \mathrm{fs}$ & $14.795 \mathrm{MHz}$ & [112] \\
\hline CVD & $35.89 \mathrm{~W}$ & $4.08 n J$ & $1570.45 \mathrm{~nm}$ & $2.43 \mathrm{ps}$ & $12.08 \mathrm{KHz}$ & [113] \\
\hline LTE & $27 \mathrm{~mW}$ & $1.4 \mathrm{n} J$ & $1560 \mathrm{~nm}$ & $6 \mathrm{~ns}$ & $388 \mathrm{KHz}$ & [114] \\
\hline CVD & $16.77 \mathrm{~mW}$ & 7.7 to $4.6 \mathrm{pJ}$ & 1570 nm & $950 \mathrm{fs}$ & $15.71 \mathrm{MHz}$ to $502.84 \mathrm{MHz}$ & [115] \\
\hline ME & $9.6 \mathrm{~mW}$ & - & $1560 \mathrm{~nm}$ & $160 \mathrm{fs}$ & $106 \mathrm{MHz}$ & [116] \\
\hline CVD & $102.5 \mathrm{~mW}$ & $0.5 \mathrm{n} J$ & $1560 \mathrm{~nm}$ & $153 \mathrm{fs}$ & $232 \mathrm{MHz}$ & [117] \\
\hline ME & $37 \mathrm{~mW}$ & - & 1562 nm & $630 \mathrm{fs}$ & $41.89 \mathrm{MHz}$ & [78] \\
\hline CVD & $2.31 \mathrm{~mW}$ & - & $1560 \mathrm{~nm}$ & $350 \mathrm{fs}$ & $54 \mathrm{MHz}$ & [118] \\
\hline ME & $1.36 \mathrm{~mW}$ & $36.5 p\rfloor$ & $1565.9 \mathrm{~nm}$ & $613 \mathrm{fs}$ & $37.2 \mathrm{MHz}$ & [119] \\
\hline ME & $2.5 \mathrm{~mW}$ & $0.16 n J$ & 1060 nm & $2.7 \mathrm{ps}$ & $9.5 \mathrm{MHz}$ & [120] \\
\hline ME & $3.9 \mathrm{~mW}$ & - & $1563 \mathrm{~nm}$ & $627 \mathrm{fs}$ & $14.3 \mathrm{MHz}$ & [121] \\
\hline LPE & $18.22 \mathrm{~mW}$ & $1.44 n J$ & $1567.29 \mathrm{~nm}$ & $1.38 \mathrm{~ns}$ & $12.66 \mathrm{MHz}$ & [91] \\
\hline ME & $2.5 \mathrm{~mW}$ & $0.16 n J$ & $1560 \mathrm{~nm}$ & $620 \pm 10 \mathrm{fs}$ & $42 \mathrm{MHz}$ & [122] \\
\hline CVD & $3 \mathrm{~mW}$ & - & $1560.3 \mathrm{~nm}$ to $1568.2 \mathrm{~nm}$ & $0.60 \mathrm{ps}$ to $1.17 \mathrm{ps}$ & $60.6 \mathrm{MHz}$ & [123] \\
\hline ME & $1.96 \mathrm{~mW}$ & 33.7pJ & $1560 \mathrm{~nm}$ & $400 \mathrm{fs}$ & $58 \mathrm{MHz}$ & [124] \\
\hline CVD & $16 \mathrm{~mW}$ & - & $1560 \mathrm{~nm}$ & $1.8 \mathrm{ps}$ & $6.9 \mathrm{MHz}$ & [125] \\
\hline
\end{tabular}

ODD optically driven deposition, CE chemically exfoliated, ME mechanically exfoliate, $L P E$ liquid phase exfoliation, $L T E$ low-temperature exfoliation

Optical deposition is an effective way to attract graphene sheets to be deposited on a fiber end. The injected laser intensity, deposition time and solution concentration are the key parameters that influence the final result of the optical deposition. According to these parameters, there are two main mechanisms that explain the different results: the optical trapping effect (acting on the micro-particles) and the thermal effect (acting on the solution), as illustrated in Fig. 9. As the incident laser intensity increases, the transmission of the graphene film also increases, which is shown in Fig. 10.

The experimental setup for optical deposition is shown in Fig. 11. A fiber laser diode (LD) at $980 \mathrm{~nm}$ generated the laser beam used for optical deposition. Then, the continuous wave traveled through the optical fiber into the 3 $\mathrm{dB}$ coupler (50:50) and split into two laser beams coupled

Table 3 Typical properties of Q-switched Er-doped fiber laser

\begin{tabular}{lllllll}
\hline Fabrication method & Average output power & Pulse energy & Center wavelength & Pulse duration & Repetition frequency & Ref \\
\hline CVD & $16 \mathrm{~mW}$ & - & $1519.3 \mathrm{~nm}$ to $1569.9 \mathrm{~nm}$ & $4.6 \mu \mathrm{s}$ & $3.2 \mathrm{KHz}$ to $9.7 \mathrm{KHz}$ & {$[125]$} \\
CVD & $14.6 \mathrm{~mW}$ & $125 \mathrm{~nJ}$ & $1563 \mathrm{~nm}$ & $1.85 \mu \mathrm{s}$ & $115 \mathrm{KHz}$ & {$[126]$} \\
CVD & $35.89 \mathrm{~W}$ & $4.08 \mathrm{~nJ}$ & $1570.45 \mathrm{~nm}$ & $2.43 \mathrm{ps}$ & $12.08 \mathrm{KHz}$ & {$[113]$} \\
EE & $14.9 \mathrm{~mW}$ & $39.4 \mathrm{~nJ}$ & $1560 \mathrm{~nm}$ & $3.56 \mu \mathrm{s}$ & $27 \mathrm{KHz}$ & {$[127]$} \\
CVD & $70 \mathrm{~nJ}$ & $1531.12 \mathrm{~nm}$ & $18.1 \mu \mathrm{s}$ & $14.9 \mathrm{KHz}$ & $17.3 \mathrm{KHz}$ & {$[128]$} \\
CVD & $40 \mathrm{~mW}$ & $9.4 \mu \mathrm{J}$ & $1556.79 \mathrm{~nm}$ & $3.56 \mu \mathrm{s}$ & {$[97]$} \\
CVD & $33 \mathrm{~W}$ & $0.615 \mathrm{~nJ}$ & $2845 \mathrm{~nm}$ & $304 \mathrm{~ns}$ & $146 \mathrm{KHz}$ & $8.288 \mathrm{MHz}$ \\
ME & $5.1 \mathrm{~mW}$ & $251.9 \mathrm{~nJ}$ & $1568.9 \mathrm{~nm}$ & $1.28 \mathrm{ps}$ & {$[38]$} \\
\hline
\end{tabular}

CVD chemical-vapour deposited, $C E$ chemically exfoliated, ME mechanically exfoliate, $L P E$ liquid phase exfoliation, $E E$ electrochemical exfoliation 
into a single mode fiber (SMF; Corning SMF -28e the mode field diameter $10.9 \mu \mathrm{m}$ at $1550 \mathrm{~nm}$ ). These two SMF are cleaved by fiber cutter to ensure the smoothness of fiber ends and then equipped with fiber ferrule. During the deposition process, one SMF was used to monitor the reflected power through an optical power meter. The other SMF was used for optical deposition, which was vertically immersed into the graphene dispersion solution. Finally, the laser beam was injected from the cleaved fiber end into the solution, driving the graphene sheets to be deposited onto the SMF end to fabricate GSA films. The shapes of the GSA films attached on the fiber end were measured by a microscope. The images of the fiber ends which deposited with graphene sheets and the transmission curves are presented in the next section. The images of the fiber ends are observed by microscope. The transmission curves are measured using a homemade modelocked laser that operates at central wavelength of 1553 $\mathrm{nm}$ with a repetition rate of $20 \mathrm{MHz}$ and a pulse duration of $500 \mathrm{ps}$.

However, it is worthwhile mentioning that optically deposited graphene saturated absorbers are affected by a number of factors, firstly, Influence of light intensity, with the increasingly injected laser intensity, under a certain range, the modulation depth increases and the transmission rate slightly increases, but the saturable intensity is less changed. In addition, influence of deposition time, with the increasing deposition time, an increasing amount of energy was absorbed by the solution, causing a larger temperature gradient. Lastly, influence of the concentration of the graphene solution, the effect of the decreasing solution concentration might be due to the combination of the decreasing of laser intensity and deposition time. Additionally, the graphene particles in the low concentration solution are smaller, which may be the reason for the increase in the saturable intensity [101].

This review studies and summarizes the properties of graphene, the preparation method of graphene saturated absorbers, and the various shapes of graphene saturated absorbers. Compared with other two-dimensional materials, graphene has the advantages of low absorption rate, extremely high thermal conductivity, good ductility and flexibility [102]. Due to these physical properties of graphene, it can be made into saturated absorbers with different shapes., And then widely used in lasers.

\section{Optical applications}

Hitherto, research on fiber lasers with 2D materials has attracted huge interest, and has translated into tremendous progress over the past few years. The inclusion of a SA into a fiber laser can initiate pulsation by Q-switching or mode-locking, where the

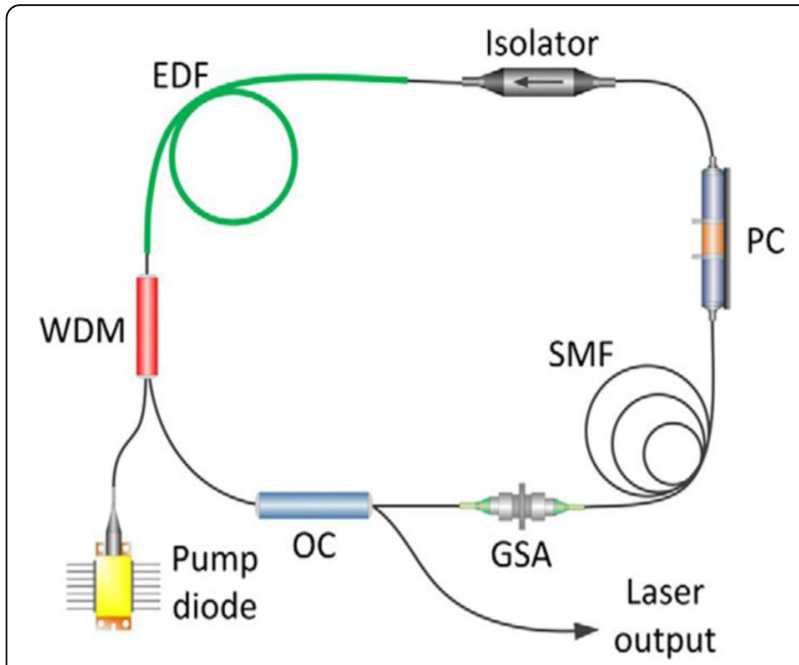

Fig. 12 Typical circuit structure of Er-doped fiber laser. Taken from [106]

output properties depend on the cavity design and saturable absorber properties. So far, graphene and graphene oxide have been widely investigated for applications in optoelectronic and photonic devices, since its unique electric and optical properties [22]. Moreover, the fast recovery time enables graphene to be used as an efficient saturable absorption element for fiber lasers. In this part, we will then focus on the optical property of graphene-based devices as well as their applications as SA devices for many kinds of fiber lasers, including Er-doped, Yb-doped, Ho-doped, Tm-doped, Pr-doped, and $\mathrm{Nd}: \mathrm{YVO}_{4-}$ doped optical fiber lasers.

In the pulse modulation process of fiber lasers, Qswitching and mode-locking technology can excite

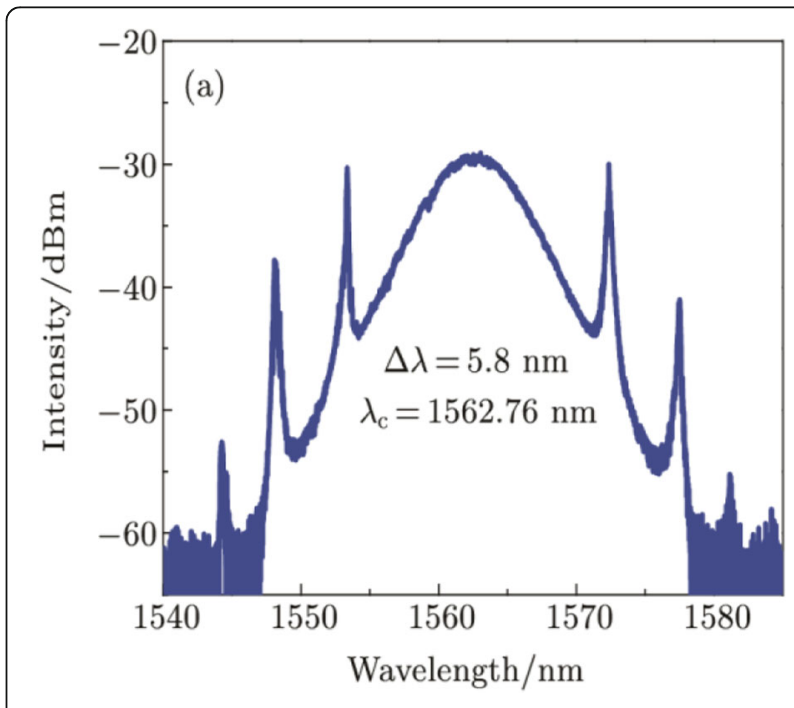

Fig. 13 Optical spectrum of Er-doped fiber laser. Taken from [106] 


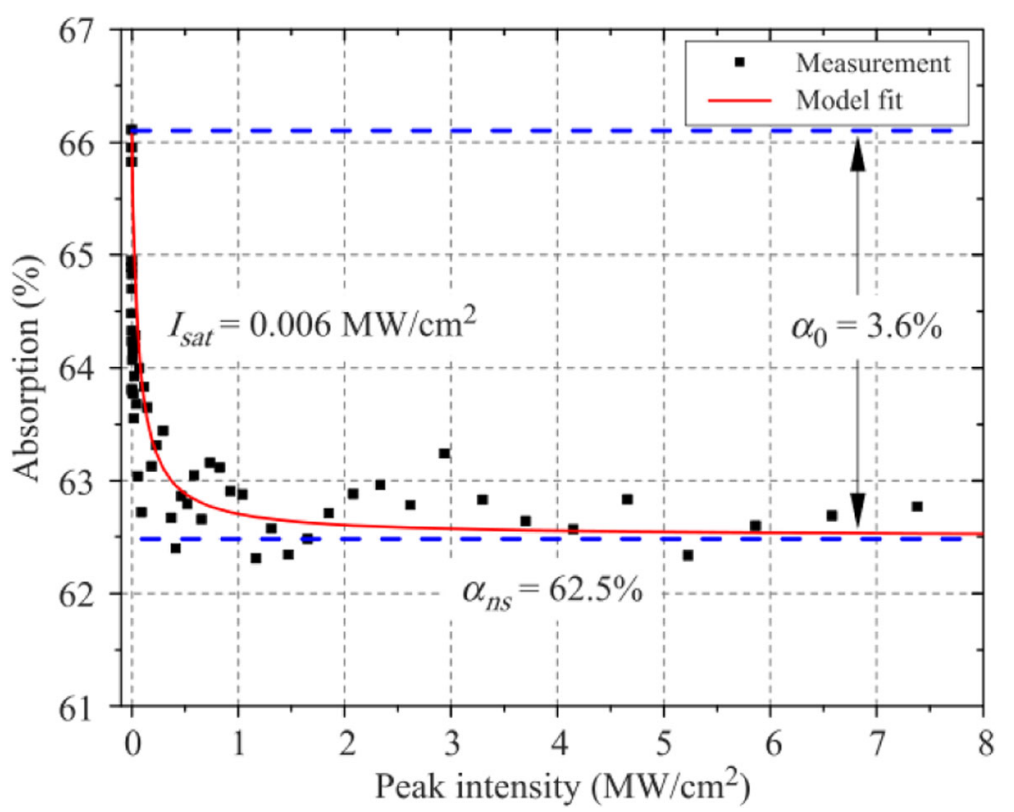

Fig. 14 Non-liner saturated absorption characteristic curve of graphene absorber. Taken from [78]

Table 4 Typical properties of mode-locked Yb-doped fiber lasers

\begin{tabular}{|c|c|c|c|c|c|c|}
\hline Fabrication method & Average output power & Pulse energy & Center wavelength & Pulse duration & Repetition frequency & Ref \\
\hline$\overline{C V D}$ & $513 \mathrm{~mW}$ & $0.81 n J$ & $1035 \mathrm{~nm}$ & $6.5 \mathrm{~ns}$ & $16.29 \mathrm{MHz}$ & {$[52]$} \\
\hline CVD & $12.09 \mathrm{~mW}$ & $4.8 n J$ & $1069.8 \mathrm{~nm}$ & $580 \mathrm{ps}$ & $0.9 \mathrm{MHz}$ & [130] \\
\hline CE & $20 \mathrm{~mW}$ & $6.4 n J$ & $1035 \mathrm{~nm}$ & $74.6 \mathrm{ps}$ & $551.5 \mathrm{KHz}$ & [132] \\
\hline CVD & $0.19 \mathrm{~mW}$ & - & $1064 \mathrm{~nm}$ & $2.3 \mathrm{~ns}$ & $8.57 \mathrm{MHz}$ & [131] \\
\hline VE & $106.5 \mathrm{~mW}$ & - & $1064.1 \mathrm{~nm}$ & $755 \mathrm{ps}$ & $1.062 \mathrm{MHz}$ & [133] \\
\hline VE & $500 \mathrm{~mW}$ & - & $1038 \mathrm{~nm}$ & $11.3 \mathrm{ps}$ & $1 \mathrm{GHz}$ & [134] \\
\hline CVD & $16.2 \mathrm{~mW}$ & - & $1064.9 \mathrm{~nm}$ & $0.52 \mathrm{~ns}$ to $60.8 \mathrm{~ns}$ & $1.078 \mathrm{MHz}$ & [135] \\
\hline CVD & $3.05 \mathrm{~mW}$ & $1.713 n J$ & $1565 \mathrm{~nm}$ & $1.8 \mathrm{ps}$ & $6.9 \mathrm{MHz}$ & {$[20]$} \\
\hline CVD & $3.05 \mathrm{~mW}$ & $1.713 n J$ & $1068.8 \mathrm{~nm}$ & $2.20 \mathrm{~ns}$ & $1.78 \mathrm{MHz}$ & {$[20]$} \\
\hline ME & $2.5 \mathrm{~mW}$ & $0.16 \mathrm{~nJ}$ & $1060 \mathrm{~nm}$ & $189 \mathrm{ps}$ & $10.05 \mathrm{MHz}$ & [120] \\
\hline CVD & $50 \mathrm{~mW}$ & $0.41 \mathrm{~nJ}$ & $1064.9 \mathrm{~nm}$ & $0.52 \mathrm{~ns}$ to $60.8 \mathrm{~ns}$ & $927 \mathrm{KHz}$ & [136] \\
\hline ME & $3 \mathrm{~mW}$ & $25.5 p J$ & $1027 \mathrm{~nm}$ & $239 \mathrm{fs}$ & $22 \mathrm{MHz}$ & [137] \\
\hline CVD & $17.4 \mathrm{~mW}$ & - & $1063 \mathrm{~nm}$ & $718 \mathrm{ps}$ & $31.86 \mathrm{MHz}$ & [138] \\
\hline CVD & $3.05 \mathrm{~mW}$ & $1.713 n J$ & $1061.8 \mathrm{~nm}$ & $2.41 \mathrm{~ns}$ & $1.78 \mathrm{MHz}$ & {$[20]$} \\
\hline VE & $9.3 \mathrm{~mW}$ & $8.68 \mathrm{~nJ}$ & $1059.7 \mathrm{~nm}$ & $340 \mathrm{ps}$ & $14 \mathrm{MHz}$ & [139] \\
\hline CVD & $20 \mathrm{~mW}$ & - & $1050 \mathrm{~nm}$ & $24 \mathrm{ps}$ & $3.7 \mathrm{MHz}$ & [125] \\
\hline CVD & $3.05 \mathrm{~mW}$ & $1.713 n J$ & $1068.8 \mathrm{~nm}$ & $2.20 \mathrm{~ns}$ & $1.78 \mathrm{MHz}$ & {$[20]$} \\
\hline $\mathrm{FH}$ & $18.63 \mathrm{~mW}$ & $3.52 \mathrm{~nJ}$ & $1044.4 \mathrm{~nm}$ & $1.10 \mu \mathrm{s}$ & $62.10 \mathrm{kHz}$ & [98] \\
\hline LPE & $253 \mathrm{~mW}$ & $3.3 n J$ & $926 \mathrm{~nm}$ & $88 \mathrm{fs}$ & $78 \mathrm{MHz}$ & {$[92]$} \\
\hline
\end{tabular}

CVD chemical-vapour deposited, $C E$ chemically exfoliated, $M E$ mechanically exfoliate, $L P E$ liquid phase exfoliation, $E E$ electrochemical exfoliation, VE vertical evaporation, $F H$ facile hydrothermal 
Table 5 Typical properties of Q-switched Yb-doped fiber lasers

\begin{tabular}{lllllll}
\hline Fabrication method & Average output power & Pulse energy & Center wavelength & Pulse duration & Repetition frequency & Ref \\
\hline ME & $8.9 \mathrm{~mW}$ & $10.3 \mathrm{~nJ}$ & $1.5 \mathrm{um}$ & $2.5 \mu \mathrm{s}$ & $2.8 \mathrm{KHz}$ to $63.0 \mathrm{KHz}$ & {$[109]$} \\
CVD & $300 \mathrm{~mW}$ & $0.83 \mu J$ & $1030 \mathrm{~nm}$ & $152 \mathrm{~ns}$ & $360 \mathrm{KHz}$ & {$[140]$} \\
CVD & $170 \mathrm{~mW}$ & $0.49 \mu J$ & $1064 \mathrm{~nm}$ & $718 \mathrm{ps}$ & $31.86 \mathrm{MHz}$ & {$[139]$} \\
LTE & $12 \mathrm{~mW}$ & $46 \mathrm{~nJ}$ & $1074.7 \mathrm{~nm}$ & $70 \mathrm{~ns}$ & $1.04 \mathrm{MHz}$ & {$[141]$} \\
LPE & $2.36 \mathrm{~mW}$ & $205 \mathrm{~nJ}$ & $1030 \mathrm{~nm}$ & $2.7 \mu \mathrm{s}$ & $141 \mathrm{KHz}$ & {$[142]$} \\
ME & $175 \mathrm{~mW}$ & $5.65 \mathrm{~nJ}$ & $1030 \mathrm{~nm}$ & $1.94 \mu \mathrm{s}$ & $147.6 \mathrm{KHz}$ \\
LPE & $2.409 \mathrm{~mW}$ & $16.3 \mathrm{~nJ}$ & $1039 \mathrm{~nm}$ & $4.37 \mu \mathrm{s}$ & {$[143]$} \\
CVD & $2.5 \mathrm{~mW}$ & - & $1060 \mathrm{~nm}$ & $18.79 \mu \mathrm{s}$ to $3.29 \mu \mathrm{s}$ & $24.51 \mathrm{KHz}$ to $39.85 \mathrm{KHz}$ & {$[145]$} \\
\hline
\end{tabular}

CVD chemical-vapour deposited, CE chemically exfoliated, ME mechanically exfoliate, $L P E$ liquid phase exfoliation, $E E$ electrochemical exfoliation, VE vertical evaporation, LTE low-temperature exfoliation

short-pulse lasers, and Q-switching and modelocking are realized by a two-dimensional material saturable absorber. The use of two-dimensional materials as the modulation element for Q-switching and mode-locking in the laser not only enables the process of Q-switching and mode-locking without external control signals, but also has a simple and reliable structure. For graphene saturable absorbers, both mode-locking and Q-switching technologies have been applied and a large number of research results have been published. This review summarizes the use of graphene as a saturable absorber in six types of fiber lasers.

\section{Er-doped fiber lasers}

Saturated absorbers made from graphene and its oxides are widely used in a variety of types of fiber lasers. It is important to highlight that Er-doped fiber lasers are widely used because of its low cost, superior performance as well as simple structure. It is found that Er-doped fiber laser is the most experimentally verified fiber laser [91, 97, 103, 104]. Table 2 summarizes the properties of different output pulses of typical Er-doped fiber lasers. A lot of experiments have validated the mode-locking capability of graphene in the $3 \mu \mathrm{m}$ wavelength region, mode-locked pulses at $2.8 \mu \mathrm{m}$ with an average output power of 18 $\mathrm{mW}$ at a repetition rate of $25.4 \mathrm{MHz}$, corresponding to a pulse energy of $0.7 \mathrm{~nJ}$ [107]. Cao et al. demonstrated a wide-band tunable passively Q-switched fiber laser by using a graphene-based SA, the stable Qswitched pulse with a tunable range from $1519.3 \mathrm{~nm}$ to $1569.9 \mathrm{~nm}$ was achieved, covering a wavelength range of over $50.6 \mathrm{~nm}$ [108]. In addition, it can be seen from the Tables 2 and 3 that the central wavelength of Er-doped fiber laser is concentrated at 1.5um. Besides, Er-doped lasers generate laser pulses with a duration from femtosecond to microsecond and high repetition rate.
The typical circuit structure of Er-doped fiber laser is shown in Fig. 12. It consists of long highly dopederbium fiber, a fiber isolator, single-mode WDM coupler, in-line fiber polarization controller, $10 \%$ output coupler and the graphene-based saturable absorber placed between two FC/APC connectors [106]. The center wavelength of the output pulse of the Er-doped fiber laser is concentrated at $1.56 \mathrm{um}$, as shown in Fig. 13 [106].

For fiber lasers, its pulse output characteristics mainly depend on the fiber material, cavity structure, working mode, pump power and type and other factors used. Then the modulation depth and saturation also have a certain influence on the pulse output of the laser, so we need to measure the size of its parameters and understand their influence on the pulse output of the fiber laser. J. SOTOR et al. proposed a graphene saturable absorber mode-locked erbiumdoped fiber laser [78]. Graphene is obtained by mechanical exfoliation, with a pulse center wavelength of $1562 \mathrm{~nm}$, a half-width band of $9 \mathrm{~nm}$, a duration of $630 \mathrm{fs}$, and a repetition frequency of 41.9

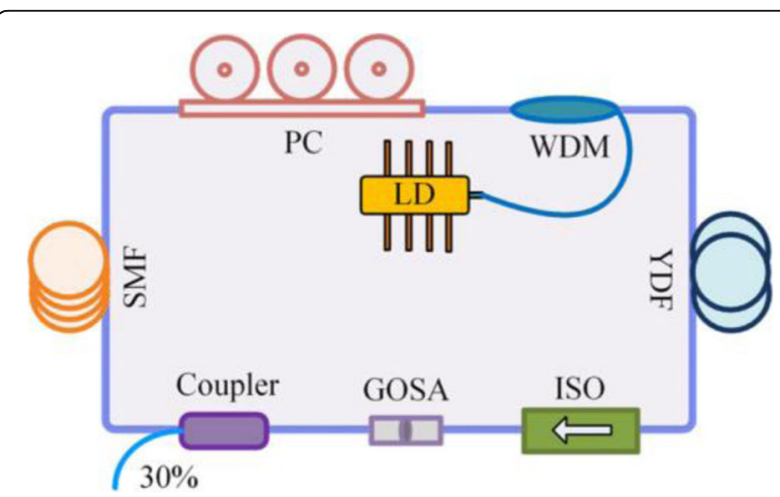

Fig. 15 The schematic configuration of the laser cavity integrated with the GOSA. PC, polarization controller; WDM, wavelength division multiplexer; YDF, Yb-doped fiber; ISO, isolator; GOSA, graphene oxide saturable absorber; SMF, single mode fiber. Taken from [133] 

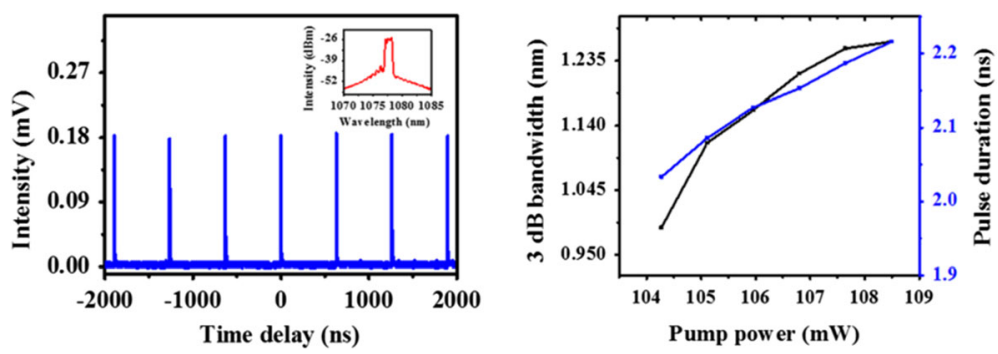

Fig. 16 Output pulse sequence diagram and output pulse characteristic curve. Taken from [133]

MHz. In the experiment, a femtosecond laser was used as the light source for them, and the signal first passed through a variable optical attenuator (VOA), and then passed through a fiber coupler. The measurement result of power dependent transmission is shown in Fig. 14.

In order to calculate the parameters of SA, the measured data is substituted into the following formula for calculation to obtain the result.

$$
\alpha(I)=\frac{\alpha_{0}}{1+\left(I / I_{\text {sat }}\right)}+\alpha_{n s}
$$

Where $\alpha(I)$ is the absorption coefficient, $I$ is the light intensity, $I_{\text {sat }}$ is the saturation intensity, $\alpha_{0}$ and $\alpha_{\text {ns }}$ are saturable and non-saturable absorption, respectively.

\section{Yb-doped fiber lasers}

Recently, the graphene used in many experiments was prepared by the chemical reduction process of graphene oxide (GO) [129]. Furthermore, graphene oxide is widely used in $\mathrm{Yb}$-doped fiber lasers. As a graphene derivative, graphene oxide not only has all the characteristics of ultrafast recovery time and broadband saturable

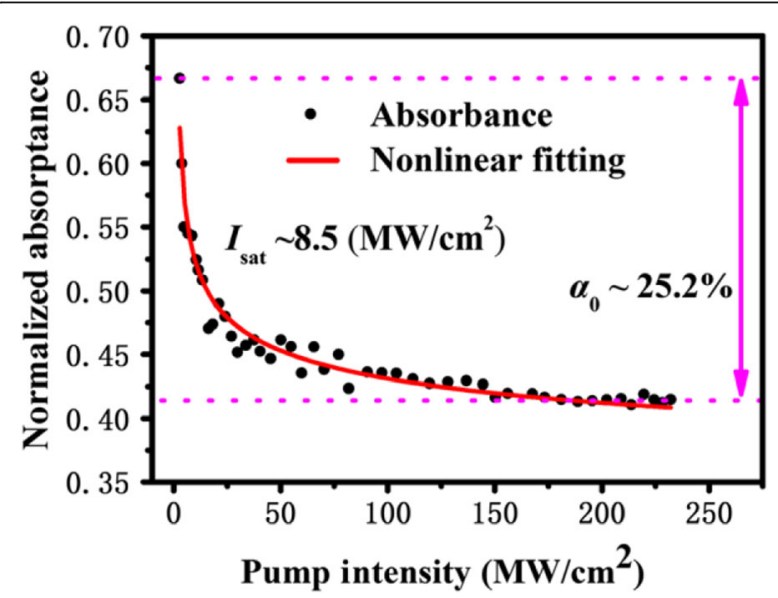

Fig. 17 Nonlinear absorbance of the utilized graphene oxide saturable absorber piece. Taken from [146] absorption, but also is much easier and cheaper to be obtained [130]. The graphene oxide for the experiment was prepared through the vertical evaporation method from chemical oxidized graphite, the same as in the previous works [131]. The flake of the oxidized graphite is about 1 to 3 atomic layers and $0.1 \mu \mathrm{m}$ to $5.0 \mu \mathrm{m}$ of the diameter.

Up to date, saturated absorbers made of graphene oxide have been used in Yb-doped fiber lasers, The results of $\mathrm{Yb}$-doped fiber laser research show that $\mathrm{Yb}$ doped fiber laser based on graphene oxide is dominated by ring cavity. In this part, the fiber lasers as well as output pulse performance of the ring cavity are introduced. The fiber laser was schematically shown in Fig. 14.

Tables 4 and 5 summarizes the nonlinear optical saturable absorption properties and their applications in laser cavities using graphene oxide in the literature to date, including the nonlinear properties of few-layer graphene oxide device to mode-lock laser cavities and great progresses for demonstrated BP-based SA devices for Qswitched lasers. Zhao et al. experimentally verified an $\mathrm{Yb}$-doped fiber laser based on a graphene saturating absorber could generate double rectangular pulses. The operating wavelength of graphene oxide-based ultrafast lasers has expended since then, covering from $1 \mu \mathrm{m}$ to

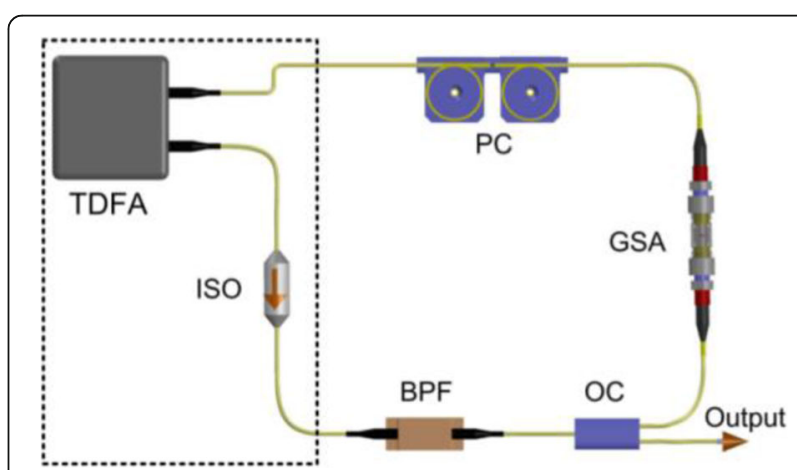

Fig. 18 TDFA-Tm-doped fiber amplifier; ISO-isolator; BPF-bandpass filter; OC-output coupler; GSA-graphene-SA; PC-polarization controller. Taken from [147] 
Table 6 Typical properties of mode-locked Tm-doped fiber lasers

\begin{tabular}{|c|c|c|c|c|c|c|}
\hline Fabrication method & Average output power & Pulse energy & Center wavelength & Pulse duration & Repetition frequency & Ref \\
\hline CVD & $1.5 \mathrm{~mW}$ & 110uJ & $1953.3 \mathrm{~nm}$ & $2.1 \mathrm{ps}$ & $16.937 \mathrm{MHz}$ & [148] \\
\hline CVD & $47 \mathrm{~mW}$ & $10.4 \mathrm{pJ}$ & $1908 \mathrm{~nm}$ & $65 \mathrm{~ns}$ & $1.82 \mathrm{MHz}$ & [52] \\
\hline CVD & $40 \mathrm{~mW}$ & $6.9 \mu \mathrm{J}$ & $2023 \mathrm{~nm}$ & $10 \mathrm{~ns}$ & $71.8 \mathrm{MHz}$ & [146] \\
\hline ME & $2 \mathrm{~mW}$ & $0.4 n J$ & $1940 \mathrm{~nm}$ & $3.6 \mathrm{ps}$ & $6.46 \mathrm{MHz}$ & [149] \\
\hline ME & $3 \mathrm{~mW}$ & - & $1852 \mathrm{~nm}$ to $1886 \mathrm{~nm}$ & $3.11 \mathrm{ps}$ & $2.68 \mathrm{MHz}$ & [150] \\
\hline CVD & $4.85 \mathrm{~mW}$ & $0.19 n J$ & $1900 \mathrm{~nm}$ & $216 \mathrm{fs}$ & $25.76 \mathrm{MHz}$ & [151] \\
\hline ME & $98 \mathrm{~mW}$ & - & $1961.6 \mathrm{~nm}$ & $1.36 \mathrm{ps}$ & $37.2 \mathrm{MHz}$ & [119] \\
\hline CVD & $1.21 \mathrm{~mW}$ & - & $1923.3 \mathrm{~nm}$ & $737 \mathrm{fs}$ & $28.25 \mathrm{MHz}$ & [118] \\
\hline LPE & $5.35 \mathrm{~mW}$ & $0.75 n J$ & $1560 \mathrm{~nm}$ & $890 \mathrm{fs}$ & $11.17 \mathrm{MHz}$ & [152] \\
\hline ME & $27.2 \mathrm{~W}$ & $0.179 n J$ & $1503.8 \mathrm{~nm}$ & $5.79 \mathrm{ps}$ & $6.93 \mathrm{MHz}$ & [153] \\
\hline CVD & $1.98 \mathrm{~W}$ & $684 n J$ & $1940.5 \mathrm{~nm}$ & $14.5 \mathrm{~ns}$ & $2.89 \mathrm{MHz}$ & [154] \\
\hline CVD & $13 \mathrm{~mW}$ & 220pJ & $1945 \mathrm{~nm}$ & $200 \mathrm{fs}$ & $58.87 \mathrm{MHz}$ & [155] \\
\hline ME & $2.87 \mathrm{~mW}$ & - & $1882 \mathrm{~nm}$ & $1.3 \mathrm{ps}$ & $17 \mathrm{MHz}$ & [156] \\
\hline
\end{tabular}

CVD chemical-vapour deposited, CE chemically exfoliated, ME mechanically exfoliate, LPE liquid phase exfoliation, EE electrochemical exfoliation

$3 \mu \mathrm{m}$. The performances of the output pulses are shown in Fig. 15. Compared with Er-doped fiber laser, this can be clearly seen in Fig. 15, and Tables 4 and 5, first of all, $\mathrm{Yb}$-doped fiber laser is mainly composed of ring cavity. In the second place, the output pulse repetition frequency generated by $\mathrm{Yb}$-doped fiber laser is lower than Er-doped fiber laser. Finally, the central wavelength of ytterbium doped fiber laser is at 1um (Fig. 16).

In this experiment, the researchers also tested the saturation characteristics of its graphene, and the results are shown in Fig. 17. The results show that the modulation depth is $25.2 \%$, the saturation intensity is $8.5 \mathrm{MW} /$ $\mathrm{cm}^{2}$, and the unsaturated loss is about $42.1 \%$. In short, the greater the modulation depth, the shorter the output laser pulse.

\section{Tm-doped fiber lasers}

With the discovery of an increasing number of optical materials through research, Tm-doped fiber has been gradually applied to ultrafast fiber lasers. Tmdoped fiber laser operating in the $1.8 \mu \mathrm{m}$ to $2.0 \mu \mathrm{m}$ wavelength range is currently one of the most important branches of laser technology and experienced tremendous progress over the last decade [146]. Moreover, it is worthwhile mentioning that all lasers have similar circuit structure. The laser cavity is schematically shown in Fig. 18. It comprises all-fiber integrated components for an environmentally robust and compact regime. Tm-doped fiber amplifier is used to amplify laser pulse signal. The optical isolator is a passive optical device which only allows oneway light to pass through. The use of optical isolator is to prevent the backward transmission light in the optical path caused by various reasons from adversely affecting the light source as well as the optical communication system. Between semiconductor laser source and optical transmission system installed an isolator, it can largely reduce the reflected light of the negative effects of spectral power output stability of light source in a high-speed direct modulation direct detection of optical fiber communication system, the transfer will generate additional noise

Table 7 Typical properties of Q-locked Tm-doped fiber lasers

\begin{tabular}{lllllll}
\hline Fabrication method & Average output power & Pulse energy & Center wavelength & Pulse duration & Repetition frequency & Ref \\
\hline ME & $162 \mathrm{~mW}$ & $0.698 \mathrm{~J}$ & $1943 \mathrm{~nm}$ & $5.08 \mu \mathrm{s}$ to $4.2 \mu \mathrm{s}$ & $15.76 \mathrm{KHz}$ to $25.08 \mathrm{KHz}$ & {$[11]$} \\
CVD & $60 \mathrm{~mW}$ & $6.9 \mu \mathrm{J}$ & $2013.5 \mathrm{~nm}$ & $88 \mathrm{fs}$ & $5.8 \mathrm{KHz}$ & {$[157]$} \\
CVD & $112.55 \mathrm{~mW}$ & $25.56 \mathrm{~nJ}$ & $1.0 \mathrm{um}$ and $1.55 \mathrm{um}$ & $6.8 \mu \mathrm{s}$ & $15.76 \mathrm{KHz}$ to $35.21 \mathrm{KHz}$ & {$[158]$} \\
LPE & $1 \mathrm{~mW}$ & $20 \mathrm{~J}$ & $1976 \mathrm{~nm}$ & $1.41 \mu \mathrm{s}$ & $32.2 \mathrm{KHz}$ to $43.0 \mathrm{KHz}$ & {$[159]$} \\
ME & $1.3 \mathrm{~mW}$ & $11 \mathrm{~nJ}$ & $1964 \mathrm{~nm}$ & $2.4 \mu \mathrm{s}$ & $61.5 \mathrm{KHz}$ & {$[160]$} \\
CVD & $0.394 \mathrm{~mW}$ & $11.03 \mathrm{~nJ}$ & $2.0 \mu \mathrm{m}$ & $6.8 \mu \mathrm{s}$ & $36.29 \mathrm{KHz}$ & {$[161]$} \\
ME & $137.4 \mathrm{~mW}$ & $0.698 \mathrm{~nJ}$ & $1943 \mathrm{~nm}$ & $4.2 \mu \mathrm{s} \mathrm{to} 5.08 \mu \mathrm{s}$ & $15.76 \mathrm{KHz}$ to $25.08 \mathrm{KHz}$ & {$[11]$} \\
\hline
\end{tabular}

CVD chemical-vapour deposited, $C E$ chemically exfoliated, ME mechanically exfoliate, $L P E$ liquid phase exfoliation, $E E$ electrochemical exfoliation 

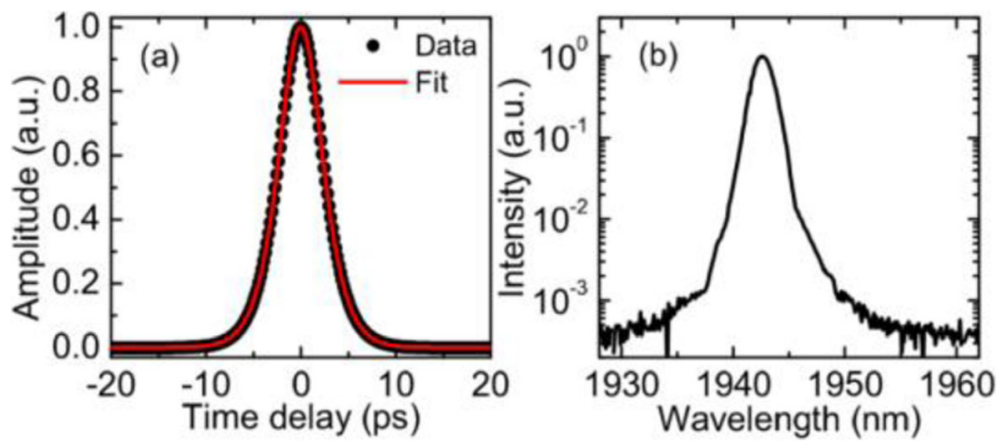

Fig. 19 a Autocorrelation, b optical spectrum. Taken from [147]

and light, which will degrade the performance of the system, so it also need isolator to eliminate. The function of band pass filter is to let the light signal pass and suppress the interference light source. Graphene saturable absorbers are used to absorb light signals in preparation for the next output. Finally, the direction of light transmission is corrected by adjusting the polarization controller to output similar laser signals.

Tables 6 and 7 summarizes the properties of different output pulses of typical Tm-doped fiber laser. It is found that mode-locking of a thulium-doped fiber laser operating at $1.94 \mu \mathrm{m}$, using a graphenepolymer based saturable absorber [11]. This is a simple, low-cost, stable and convenient laser oscillator for applications where eye-safe and low-photonenergy light sources are required, such as sensing and biomedical diagnostics [162]. The autocorrelation of the output pulse, and the corresponding optical spectrum are plotted in Fig. 19.

In general, Tm-doped fiber lasers, with five representative spectra at the wavelength of $1876,1908,1943,1953$, and $2023 \mathrm{~nm}$ presented [11, 148, 149, 157, 162]. In previous research experiments, the graphene saturation characteristic measurement device and the result with the center wavelength of the output pulse of $\sim 2000 \mathrm{~nm}$ are shown in Fig. 20. The results show that the modulation depth is $1.5 \%$ and the saturation intensity is $0.0035 \mathrm{MW} / \mathrm{cm}^{2}[161]$.

(a)

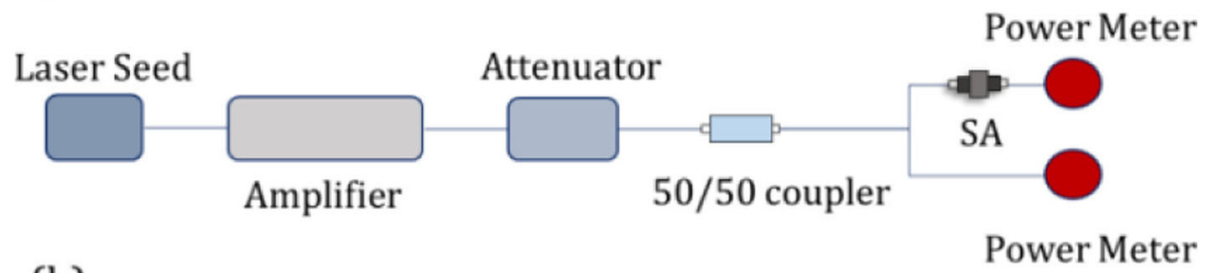

(b)

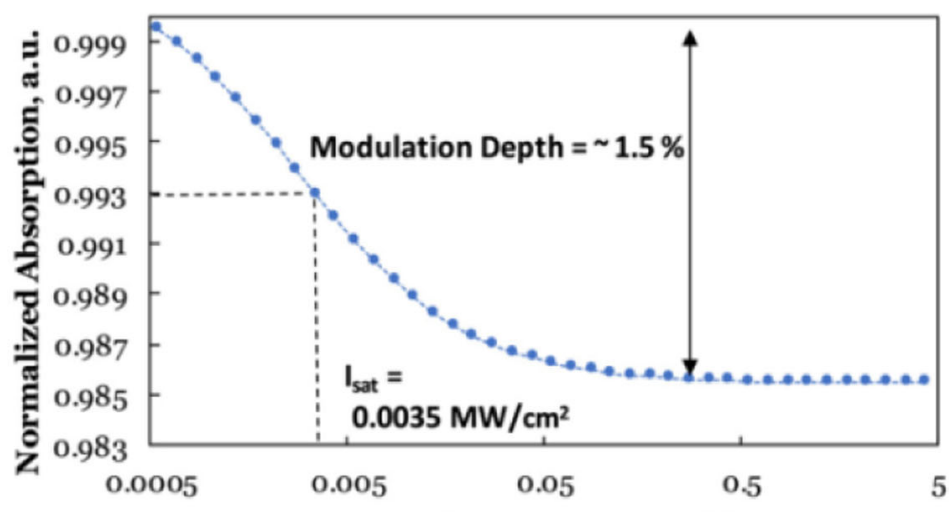

Pump Peak Intensity, MW $/ \mathrm{cm}^{2}$

Fig. 20 a Setup for the nonlinear absorption measurement. b Curve-fitted non-linear saturable absorption property of the graphene SA. Taken from [161] 


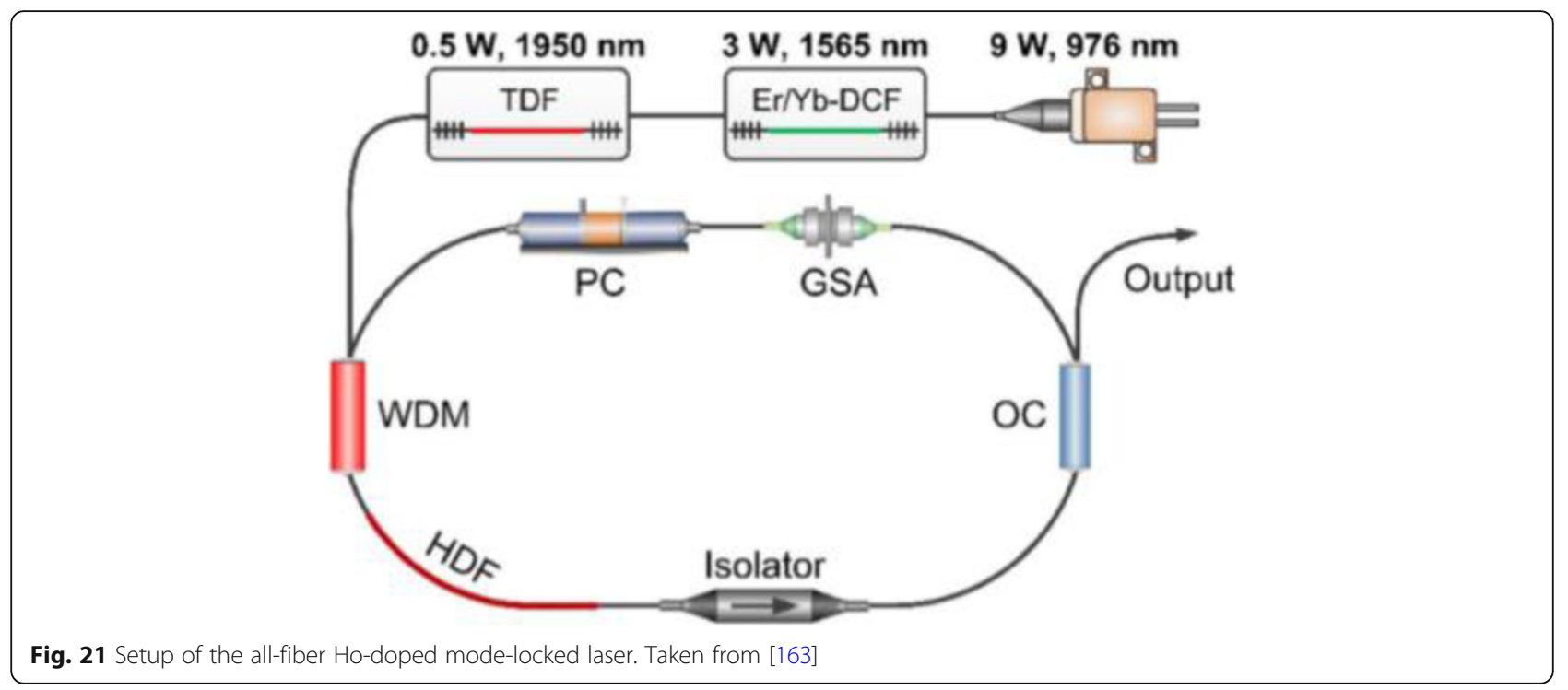

\section{Ho-doped fiber lasers}

Ultrafast fiber laser operating below $2 \mu \mathrm{m}$ based on different mode-locking mechanisms: nonlinear amplifying loop mirror, nonlinear polarization evolution (NPE), semiconductor saturable mirrors (SESAM), single wall carbon nanotubes (SWCNT), graphene, topological insulators, and black phosphorus were demonstrated [94, 163]. However, the number of laser sources operating at wavelengths longer than $2 \mu \mathrm{m}$ is very limited. Recently, the first allfiber Ho-doped oscillator based on a real SA has been used in fiber lasers at the first time.

The setup of the all-fiber Ho-doped mode-locked oscillator is depicted in Fig. 21. The $1 \mathrm{~m}$ long piece of
Ho-doped gain fiber (HDF) was pumped by $1950 \mathrm{~nm}$ and $2080 \mathrm{~nm}$ wavelength division multiplexer (WDM) (both components are custom) by a continuous wave (CW) fiber laser delivering $0.5 \mathrm{~W}$ at $1950 \mathrm{~nm}$. The resonator was arranged in a ring configuration, where the codirectional propagation of the signal and pump was forced by a fiber isolator. The signal was coupled out from the cavity using fiber output couplers with coupling ratios $(\mathrm{CR})$ varying from $10 \%$ to $70 \%$. Because the designed resonator was based on standard single-mode fibers, a polarization controller (PC) was spliced to the cavity to initiate the laser operation in mode-locking regime. The GSA was

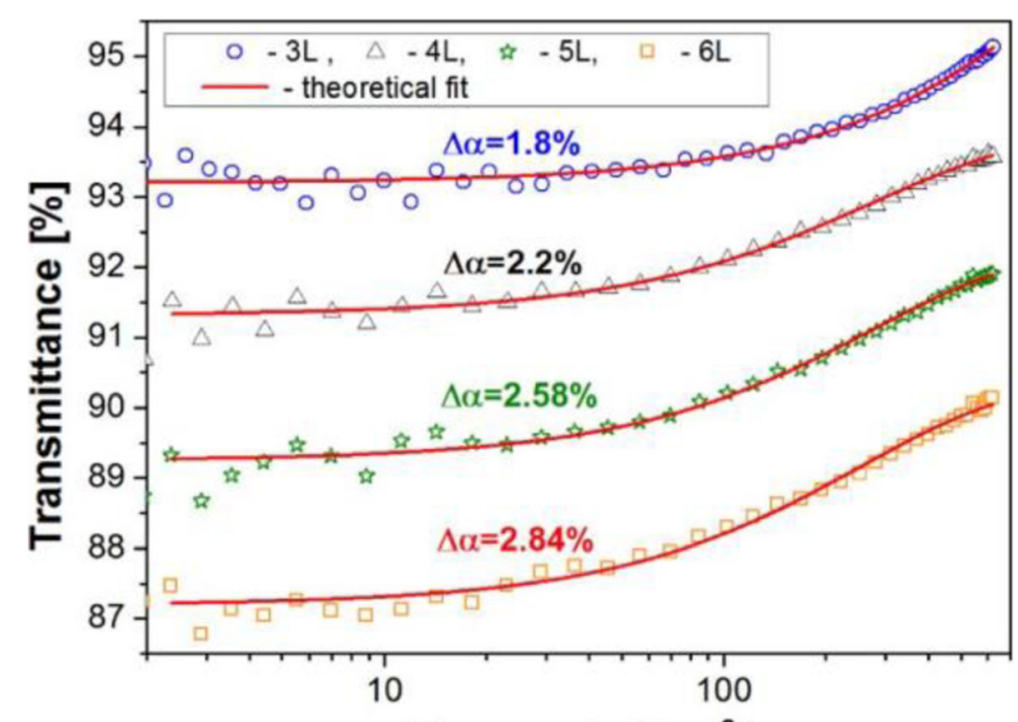

Fluence $\left[\mu \mathrm{J} / \mathrm{cm}^{2}\right]$

Fig. 22 Measured energy dependent transmittance of GSAs containing of 3, 4, 5, and 6 layers of graphene. Taken from [163] 
Table 8 Typical properties of Ho-doped fiber lasers

\begin{tabular}{lllllll}
\hline Fabrication method & Average output power & Pulse energy & Center wavelength & Pulse duration & Repetition frequency & Ref \\
\hline CVD & $54 \mathrm{~mW}$ & $2.55 \mathrm{~nJ}$ & $2060 \mathrm{~nm}$ & $190 \mathrm{fs}$ & $21 \mathrm{MHz}$ & {$[94]$} \\
CVD & $180 \mathrm{~mW}$ & $0.44 \mu J$ & $2080 \mathrm{~nm}$ & $826 \mathrm{fs}$ & $38 \mathrm{MHz}$ & {$[163]$} \\
ME & $52 \mathrm{~mW}$ & - & $1190 \mathrm{~nm}$ & $5.7 \mu \mathrm{s}$ & $24 \mathrm{KHz}$ & \\
CVD & $0.4 \mathrm{~mW}$ & $20 \mathrm{pJ}$ & $1976 \mathrm{~nm}$ & $1.41 \mu \mathrm{s}$ & $19.978 \mathrm{MHz}$ & {$[164]$} \\
\hline
\end{tabular}

CVD chemical-vapour deposited, ME mechanically exfoliate

made by a graphene/poly (methyl methacrylate) (PMMA) composite inserted between two fiber connectors [163].

Figure 22 depicts the use of a $1550 \mathrm{~nm}$ all-fiber device to measure the power-dependent light transmittance of a saturated absorber containing 3 to 6 layers of graphene. The results show that the modulation depth increases as the number of graphene layers increases, while the saturation intensity decreases.

Table 8 summarizes the properties of different output pulses of typical Ho-doped fiber lasers. We can learn from the data in the table that all fiber Hodoped mode-locked laser utilizedfew-layer graphene as saturable absorber. The laser was capable of generating optical solitons in the $2067 \mathrm{~nm}$ to $2081 \mathrm{~nm}$ spectral range with the shortest duration of $810 \mathrm{fs}$. The average output power and the pulse energy at the level of $44 \mathrm{~mW}$ and $1.3 \mathrm{~nJ}$ were obtained, respectively. The pulse energy is the highest reported for the Ho-doped laser using GSA, while the $811 \mathrm{fs}$ pulses are the shortest generated from a Ho-doped soliton laser.

\section{Pr-doped fiber lasers}

Since its discovery, graphene has been widely used as a saturation absorber in several common fiber lasers. In addition, it is also involved in Pr-doped fiber lasers. For this part, we will introduce the Pr-doped fiber laser. The technique used in $\mathrm{Pr}$-doped fiber laser is Q-switching, it is experimental setup of a Qswitched Pr-doped fiber laser with graphene is shown in Fig. 23. On the one hand, the fiber laser adopts linear cavity structure, which has the advantages of simple structure and low cost. The graphene has a transmittance of $95.2 \%$ at $636 \mathrm{~nm}$, indicating that it has two or more layers. The Pr-doped fiber laser has a central wavelength of $637 \mathrm{~nm}$ as shown in Fig. 24 . However, because the amplitude of its output light source is not equal, the development of this kind of fiber laser is limited to a large extent. Although this kind of laser has some defects, perhaps after people's thorough research and discussion, this kind of fiber laser can be widely used in many fields $[49,75,77]$ (Fig. 25).

\section{$\mathrm{Nd}: \mathrm{YOV}_{4}$-doped fiber lasers}

To date, an increasing number of materials can be used in a variety of fiber lasers. Furthermore, Tengfei Dai et al. demonstrated the Nd:YOV ${ }_{4}$-doped fiber laser application in optical filed [39]. In this section, we discuss the optical source properties of this kind of fiber laser. Frist of all, the experimental setup of the $\mathrm{Nd} \mathrm{YOV}_{4}$ doped fiber laser is shown in Fig. 26. Compared with several other types of fiber lasers, its structure is very simple and uses the linear cavity.

In order to further study the characteristics of the output laser, a digital oscilloscope is used to observe and record the time trajectory of the pulse. The output waveform of the single pulse and the corresponding pulse sequence are shown in Fig. 27. When the pump power is $13.2 \mathrm{~W}$, the pulse time path is observed and recorded by the digital oscilloscope. A stable Q-switched pulse with a

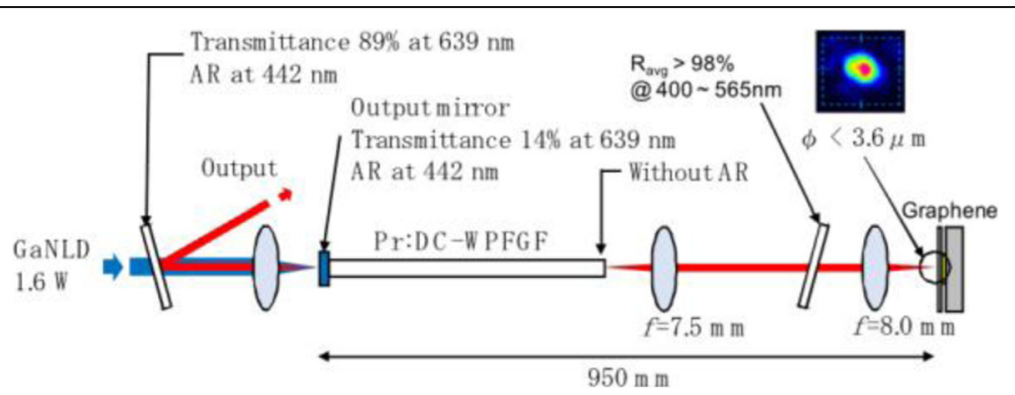

Fig. 23 Experimental Setup of Q-switching Pr-doped fiber laser. Taken from [77] 
pulse width of $280 \mathrm{~ns}$, and a repetition rate of $1.29 \mathrm{MHz}$ is obtained. Figure 28 is the output laser spectrum of continuous wave and Q-Switched operation when the pump power is $2.2 \mathrm{w}$. The median wave length of the output spectrum of the laser is $1063.78 \mathrm{~nm}$.

\section{Analysis and summary of multi-wavelength}

In this review, it is found through summary that using different types of pump diodes and adjusting their power can achieve dual-wavelength pulse output. This article summarizes part of the research results as shown in Table 9, most of them use singlewalled carbon nanotube saturable absorbers, erbiumdoped fiber lasers and other optical devices to form ring cavity lasers. It can be seen that the center wavelength of the two pulses is distributed $\sim 1500$ $\mathrm{nm}$, the repetition frequency ranges from a few $\mathrm{MHz}$ to tens of $\mathrm{MHz}$, and the pulse duration ranges from femtoseconds to microseconds. Among the research results that have been summarized, Xin Zhang et al. published a passively mode-locked multi-wavelength output laser based on a single-walled carbon nanotube saturable absorber (SWNT-SA) [183]. The experimental device is shown in Fig. 29. The experimental device uses a ring-shaped cavity, including several commonly used and more important optical components. The purpose of connecting the isolater in the fiber ring cavity is to ensure that the light can travel in one direction in the ring cavity and eliminate the backscatter of the laser. The polarization controller realizes different polarization orientation states. The pump diode provides a light source of specific wavelength and power, and realizes the output of multiple wavelength pulses by adjusting its power. Erbium-doped fiber and single-mode fiber are used as gain media. The experimental instruments used to measure the output pulse mainly include power meters, spectrum analyzers, digital oscilloscopes, photodiode detectors and radio frequency analyzers.

\section{Conclusion}

In this review, we summarize six different doped fiber lasers and three types of graphene-based saturable absorbers, which are the most widely used graphene saturated absorbers (GSA). Firstly more importantly, it is more essential that the six kinds of fiber lasers could generate well optical properties of optical source, such as high repetition frequency, essay preparation and low cost. Besides, most of fiber lasers use modelocking and ring cavity, and the fiber lasers structure all most includes PC, GSA (graphene saturable absorber), coupler, LD, SMF, and doped fiber. Meanwhile, the fiber lasers are used in various filed.

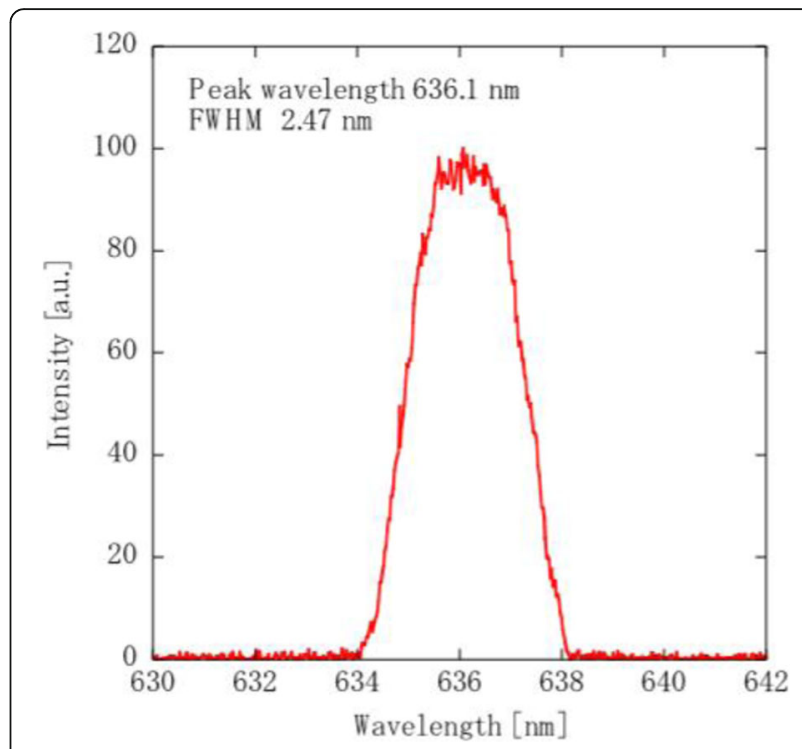

Fig. 24 Spectra of 637-nm-band Q-switched pulse laser oscillation. Taken from [77]

Many researches on two-dimensional materials have demonstrated the properties of various materials, providing a large platform to future optical applications and promoting the development of fiber lasers. In ultrafast fiber laser applications, the properties of a variety of two-dimensional nanomaterials, due to their excellent photonic and optoelectronic properties are particularly significant for the fabrication of multifunctional SA devices in an simple and efficient manner.

Graphene and its oxides have attracted much attention due to their optical properties, for instance, super fast recovery time, simple structure and low cost. Therefore,

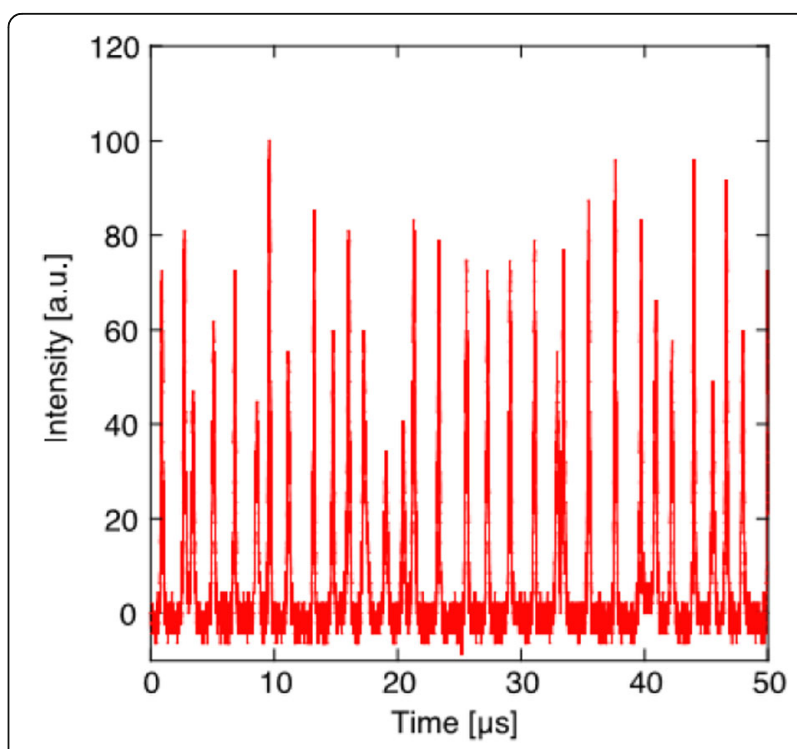

Fig. 25 Pulse waveform of $637 \mathrm{~nm}$ band Q-switched pulse laser oscillation. Taken from [77] 


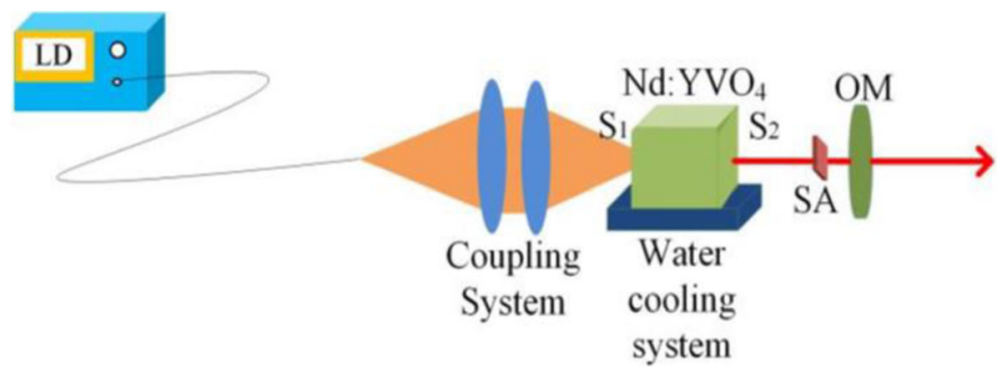

Fig. 26 Experimental layout of the passively Q-switched laser based on Graphene-SA. Taken from [165]

the reported graphene SA photonics can be used in mode-locked and Q-switched fiber lasers to generate short pulses at the $\mathrm{KHz}-\mathrm{MHz}$ repetition rate, or even at the $\mathrm{GHz}$ frequency, with the pulse duration ranging from fs to us, applications in various doped fiber lasers. In terms of device integration strategies, an increasing number of processing technologies including embedded transparent polymer films as well as photoconductive optical deposition on optical devices have been demonstrated on various platforms.

The growing interest of exploring the broad and increasing catalogue of available 2D nanomaterials encourages the researchers to search for new physics and technology breakthroughs. An increasing number of 2D nanomaterials have been demonstrated as ultra-fast wideband optical switches for mode-locked and Qswitched fiber lasers, since the reliability of these 2D nanomaterial based ultrafast optical switches are required to be proven to the same degree as incumbent saturable absorber technology like SESAM. Furthermore, it is worth mentioning that the D-shaped graphene saturable absorber is embedded in a ring cavity to generate a stable and well performance light source pulse, central wavelength focus on $1.5 \mathrm{um}$, repetition rate is above $\mathrm{MHz}$, with the pulse duration ranging from femtosecond to microsecond. A number of problems are pressing research problems to be addressed, including the relatively high unsaturated loss and laser cavity length of twodimensional saturated nanoabsorbent materials, which limits the efficiency of fiber based light sources.

In the future, the use of graphene saturable absorbers in fiber lasers will transform the laser pulse generation by changing the number of layers. Moreover, heterogeneous structures made of different single-layer stacks may be the frontier and direction of future fiber laser source research, as they combine multiple different two-dimensional nanomaterials layers to create a new material system with significant optical properties that can be used in ideal applications. The development of quantum mechanics and materials science has provided theoretical tools to analyze size-dependent behavior on the nanoscale of such materials. On the other hand, graphene can be combined with a variety of gases or liquids with good optical properties to make saturated absorbers for fiber lasers, which will become the key direction and development trend of future research. So far, researchers have considered how to improve
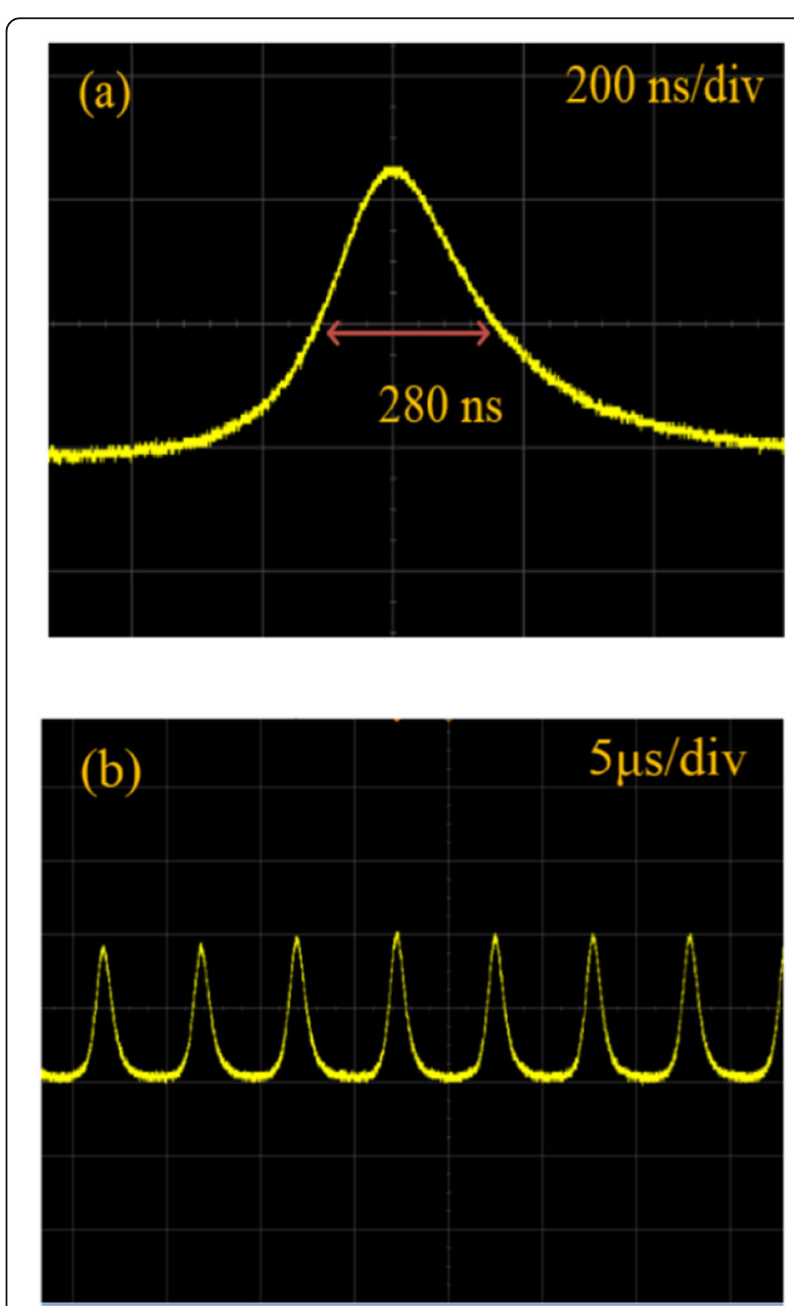

Fig. 27 Output characteristics of pulsed laser at the absorbed pump power of $13.2 \mathrm{~W}$. a Single pulse waveform of $200 \mathrm{~ns} / \mathrm{div}$; b Pulse sequence of $5 \mu \mathrm{s} / \mathrm{div}$. Taken from [165] 


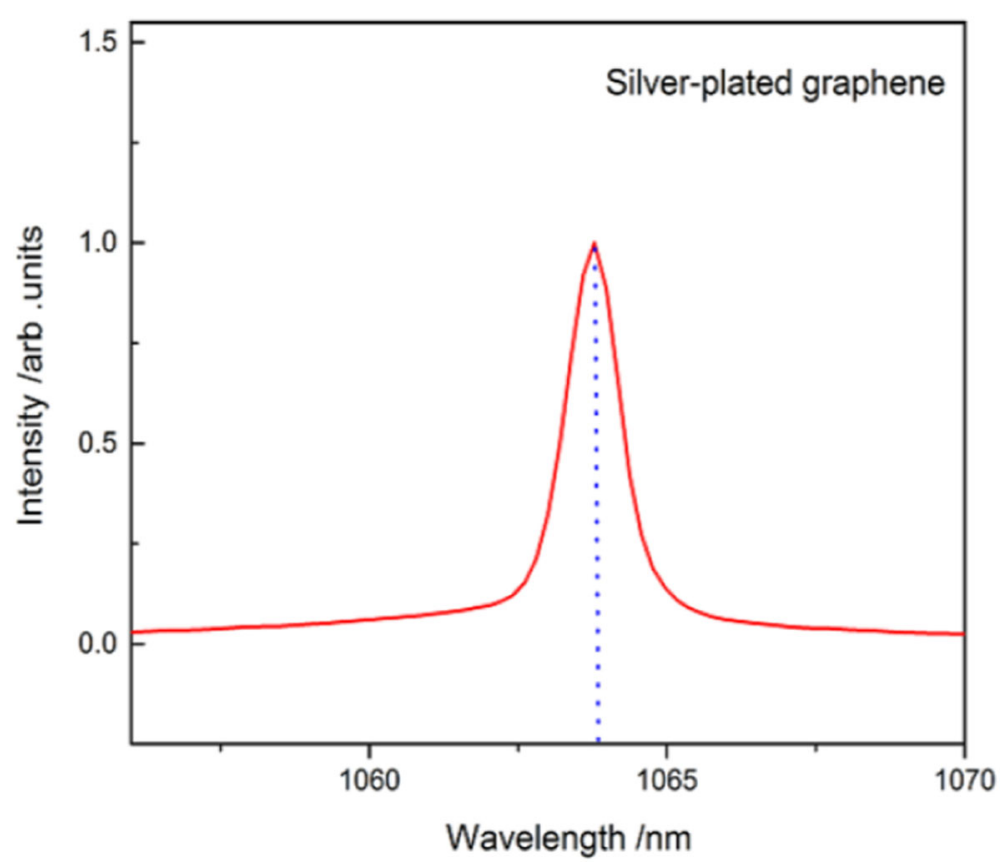

Fig. 28 Laser output spectrogram. Taken from [165]

Table 9 Summary of dual-wavelength fiber laser pulse output

\begin{tabular}{|c|c|c|c|c|c|c|c|c|c|c|c|}
\hline No & Saturated absorber type & Fiber type & $\lambda 1(\mathrm{~nm})$ & $\mathrm{f}_{1}(\mathrm{MHz})$ & $t_{1}$ & FWHM $1(\mathrm{~nm})$ & $\lambda_{2}(\mathrm{~nm})$ & $\mathrm{f}_{2}(\mathrm{MHz})$ & $t_{2}$ & FWHM $2(\mathrm{~nm})$ & Ref \\
\hline 1 & SWNT & Er & 1533 & 52.743 & - & 2.7 & 1544 & 52.744 & - & 3.3 & {$[166]$} \\
\hline 2 & SWNT & Er & 1534.0 & 32.3 & - & 7.5 & 1547.5 & 32.3 & - & 6.9 & [167] \\
\hline 3 & SWNT & Er & 1530.8 & 28.2 & - & 1.9 & 1547.6 & 28.2 & - & 2.1 & [168] \\
\hline 4 & SWNT & Er & 1531.4 & 32.066 & $0.2 \mathrm{ps}$ & 2.2 & 1556.1 & 32.068 & $0.4 \mathrm{ps}$ & 3.3 & [169] \\
\hline 5 & SWNT & Er & 1574.6 & 21.174 & $1.27 \mathrm{ps}$ & 4.5 & 1591.9 & 21.173 & $1.08 \mathrm{ps}$ & 4.5 & [170] \\
\hline 6 & SWNT & Er & 1532 & $32.3 \mathrm{KHz}$ & 6us & - & 1558 & $66.2 \mathrm{KHz}$ & 9us & - & [171] \\
\hline 7 & $W_{2}$ & $\mathrm{Yb}$ & 1030.2 & $22.73 \mathrm{KHz}$ & 4.6us & 1.6 & 1034.5 & $23.01 \mathrm{KHz}$ & 4.1us & 0.9 & [172] \\
\hline 8 & SWNT & $\mathrm{Er}$ & 1532 & $23.8 \mathrm{KHz}$ & 4.8us & - & 1558 & $66.2 \mathrm{KHz}$ & 2.6us & - & [173] \\
\hline 9 & SWNT & Er & 1531.4 & $32.066 \mathrm{~Hz}$ & $0.2 \mathrm{ps}$ & 2.2 & 1556.1 & $32.068 \mathrm{~Hz}$ & $0.4 \mathrm{ps}$ & 3.3 & [174] \\
\hline 10 & SWNT & Er & 1532.4 & 15.752 & 24us & - & 1555.1 & 15.752 & 10us & - & [175] \\
\hline 11 & SWNT & $\mathrm{Er}$ & 1558.1 & 32.9804 & - & 3.8 & 1557.7 & 32.9807 & - & 4.4 & [176] \\
\hline 12 & - & Er & 1532.8 & 46.585 & - & 3.5 & 1564.9 & 46.583 & - & 3.4 & [177] \\
\hline 13 & SWNT & $\mathrm{Er}$ & 1532 & 34.5188 & $1.71 \mathrm{ps}$ & - & 1547 & 34.5182 & $1.05 \mathrm{ps}$ & - & [178] \\
\hline 14 & SWNT & Er & 1530 & 9.08980 & - & - & 1558 & 9.0930 & - & - & [179] \\
\hline 15 & SWNT & $\mathrm{Er}$ & 1559.6 & 24.41 & - & 1.0 & 1564.9 & 24.37 & - & 1.2 & [180] \\
\hline 16 & SWNT & Er & 1529.0 & 30.8 & 1.83 & 1.9 & 1559.7 & 30.8 & 3.06 & 1.3 & [181] \\
\hline 17 & SWNT & $\mathrm{Er}$ & 1595.6 & 5.19 & - & 1.6 & 1598.7 & 5.19 & - & 1.6 & [182] \\
\hline 18 & SWNT & $\mathrm{Er}$ & 1532 & 9.09 & $0.99 \mathrm{ps}$ & 2.7 & 1557 & 9.08 & $0.95 \mathrm{ps}$ & 3 & [183] \\
\hline 19 & SWNT & $\mathrm{Er}$ & 1534 & - & $0.46 \mathrm{ps}$ & & 1549 & - & $0.67 \mathrm{ps}$ & & [184] \\
\hline 20 & SWNT & $\mathrm{Er}$ & 1533.5 & 64.55 & $100 \mathrm{fs}$ & 2.2 & 1542.8 & 64.55 & $100 \mathrm{fs}$ & 3.3 & [185] \\
\hline 21 & SWNT & $\mathrm{Er}$ & 1532.2 & 9.09 & $0.96 \mathrm{ps}$ & 2.7 & 1558.5 & 9.08 & $0.85 \mathrm{ps}$ & 3 & [186] \\
\hline 22 & SWNT & $\mathrm{Er}$ & 1532.4 & 15.752 & $1.56 \mathrm{ps}$ & - & 1555.1 & 15.753 & $1.15 \mathrm{ps}$ & - & [187] \\
\hline
\end{tabular}

SWNT single-wall carbon nanotube, Er Erbium-doped fiber, $Y b$ Ytterbium-doped fiber 


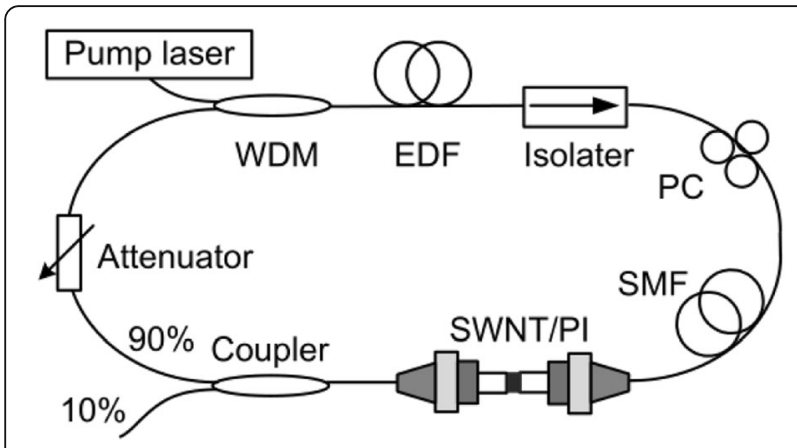

Fig. 29 Multi-wavelength pulse output experimental device setup. Taken from [183]

manufacturing techniques to scale up to accommodate integration with various optical devices. Twodimensional nanomaterials will have revolutionary technological implications in photonics, such as graphene and its oxides, in line with current research interests.

\section{Abbreviations \\ SESAM: Semiconductor saturation absorption mirror; SA: Saturable absorber; CNTs: Carbon nanotubes; TMDs: Transition metal dichalcogenides; Tis: Topological insulators; TMO: Transition metal oxides; BP: Black phosphorous; 2D: Two-dimensional; AFM: Atomic force microscopy; LPE: Liquid phase exfoliation; CVD: Chemical vapor deposition; PVA: Polyvinyl alcohol; DMF: Dimethyl formamide; HOPG: Highly ordered pyrolytic graphite; UV: Ultraviolet; LD: Laser diode; WDM: Wavelength Division Multiplexer; ODD: Optically driven deposition; CE: Chemically exfoliated; ME: Mechanically exfoliate; GO: Graphene oxide; EE: Electrochemical exfoliation; VE: Vertical evaporation; FH: Facile hydrothermal; CW: Continuous wave; CR: Coupling ratios; PC: Polarization controller; PMMA: Graphene/poly (methyl methacrylate); SWNT: Single-wall carbon nanotube}

\section{Acknowledgements}

The author would like to thank all colleagues for their hard work.

\section{Authors' contributions}

$\mathrm{XP}$ is the main author of the current paper. XP contributed to the development of the ideas, design of the study, result analysis, and article writing. YY finished the analysis and interpretation of data and drafted the manuscript. All authors read and approved the final manuscript.

\section{Authors' information}

$X_{i}$ Peng is currently a master student at Harbin University of Science and Technology. His current research interests include optical fiber and communication and information systems.

Yixin Yan received a PhD in measurement and control technology and instrumentation from Harbin University of Science and Technology in 2013. Her current research interests include embedded systems and applications, data mining and applications, software engineering, optics and its applications in medicine.

\section{Funding}

This work is supported in part by Heilongjiang Province Key Laboratory of Laser Spectroscopy Technology and Application, Harbin University of Science and Technology.

\section{Availability of data and materials} Not Applicable.

\section{Declaration}

\section{Competing interests}

The authors declare that they have no competing interests.

Received: 6 December 2020 Accepted: 7 July 2021

Published online: 03 August 2021

\section{References}

1. Ahmad, H., Ooi, S.I., Tiu, Z.C., Ismail, M.F., Zulkfili, M.Z., Yasin, M., Thambiratnam, K.: Passively Q-switched thulium fluoride fiber laser operating in S-band region using $\mathrm{N}$-doped graphene saturable absorber. Indian J. Phys. (2020). https://doi.org/10.1007/s12648-020-01815-2

2. Chakravarty, U., Gurram, S., Kuruvilla, A., Upadhyaya, B.N., Bindra, K.S.: Short pulse generation in active Q-switched Yb-doped all fiber laser and its amplification. Opt. Laser Technol. 109, 186-192 (2019). https://doi.org/10.1 016/j.optlastec.2018.07.074

3. Li, L., et al.: Mode-Locked Er-Doped Fiber Laser by Using MoS2/SiO2 Saturable Absorber. Nanoscale Res. Lett. 14(1), 59 (2019). https://doi.org/1 0.1186/s11671-019-2888-z

4. Salman, A.A., Al-Janabi, A.: Triple-wavelength Q-switched ytterbium-doped fiber laser based on tungsten oxide as saturable absorber. Microw. Opt. Technol. Lett. 62(6), 2257-2262 (2020). https://doi.org/10.1002/mop.32324

5. Salman, A.M., Al-Janabi, A.: Nickel nanoparticles Saturable absorber for multiwavelength pulses generation in ytterbium-doped Fiber laser. Fiber Integr. Opt. 39(3), 109-121 (2020). https://doi.org/10.1080/01468030.2020.1 768607

6. Song, H., Wang, D., Wang, Q., Li, L.: Passively Q-switched all-fiber lasers generating cylindrical vector beams with 2-dimensional material saturable absorbers. Opt. Fiber Technol. 45, 71-76 (2018). https://doi.org/10.1016/j. yofte.2018.06.001

7. Wang, S., Sun, X., Luo, Y., Peng, G.: Surface plasmon resonance sensor based on D-shaped hi-bi photonic crystal fiber. Opt. Commun. 467, 125675 (2020). https://doi.org/10.1016/j.optcom.2020.125675

8. Pathak, A.K., Singh, V.K.: Theoretical assessment of D-shaped optical fiber chemical sensor associated with nanoscale silver strip operating in nearinfrared region. Opt. Quantum Electron. 52(4), (2020). https://doi.org/10.1 007/s11082-020-02316-6

9. Yu, H., Chong, Y., Zhang, P., Ma, J., Li, D.: A D-shaped fiber SPR sensor with a composite nanostructure of MoS2-graphene for glucose detection. Talanta. 219, 121324 (2020). https://doi.org/10.1016/j.talanta.2020.121324

10. Zakaria, R., Mezher, M.H., Zahid, A.Z.G., Rohizat, N.S., Patel, S.K., Amiri, I.S.: Nonlinear studies of graphene oxide and its application to moisture detection in transformer oil using D-shaped optical fibre. J. Mod. Opt. 67(7), 619-627 (2020). https://doi.org/10.1080/09500340.2020.1760387

11. Kasim, N., Latiff, A.A., Rusdi, M.F.M., Hisham, M.B., Harun, S.W., Razak, N.F.: Short-pulsed Q-switched thulium doped fiber laser with graphene oxide as a saturable absorber. Optik. 168, 462-466 (2018). https://doi.org/10.1016/j. ijleo.2018.04.117

12. Mohammed, D.Z., Al-Janabi, A.H.: Passively Q-switched erbium doped fiber laser based on double walled carbon nanotubes-polyvinyl alcohol saturable absorber. Laser Phys. 26(11), 115108 (2016). https://doi.org/10.1088/1054$660 x / 26 / 11 / 115108$

13. Mohsin Al-Hayali, S.K., Hadi Al-Janabi, A.: Triple-wavelength passively Qswitched ytterbium-doped fibre laser using zinc oxide nanoparticles film as a saturable absorber. J. Mod. Opt. 65(13), 1559-1564 (2018). https://doi. org/10.1080/09500340.2018.1455922

14. Jariwala, D., Sangwan, V.K., Lauhon, L.J., Marks, T.J., Hersam, M.C.: Emerging device applications for semiconducting two-dimensional transition metal dichalcogenides. ACS Nano. 8(2), 1102-1120 (2014). https://doi.org/10.1021/ $\mathrm{nn} 500064 \mathrm{~s}$

15. Chen, B., Zhang, X., Wu, K., Wang, H., Wang, J., Chen, J.: Q-switched fiber laser based on transition metal dichalcogenides $\operatorname{MoS}(2)$, MoSe (2), WS (2), and WSe (2). Opt. Express. 23(20), 26723-26737 (2015). https://doi.org/10.13 64/OE.23.026723

16. Mak, K.F., Shan, J.: Photonics and optoelectronics of 2D semiconductor transition metal dichalcogenides. Nat. Photonics. 10(4), 216-226 (2016). https://doi.org/10.1038/nphoton.2015.282

17. Tan, C.-D., Min, F., Wang, M., Zhang, H.-R., Zhang, Z.-H.: Discovering patterns with weak-wildcard gaps. IEEE Access. 4, 4922-4932 (2016). https://doi.org/1 0.1109 /access.2016.2593953 
18. Wang, Q.H., Kalantar-Zadeh, K., Kis, A., Coleman, J.N., Strano, M.S.: Electronics and optoelectronics of two-dimensional transition metal dichalcogenides. Nat. Nanotechnol. 7(11), 699-712 (Nov 2012). https://doi.org/10.1038/nna no.2012.193

19. Yun, W.S., Han, S.W., Hong, S.C., Kim, I.G., Lee, J.D.: Thickness and strain effects on electronic structures of transition metal dichalcogenides: $2 \mathrm{H}$ MX2semiconductors (M=Mo, W;X=S, Se, Te). Phys. Rev. B. 85(3), (2012). https://doi.org/10.1103/PhysRevB.85.033305

20. Zhao, N., et al.: Dual-wavelength rectangular pulse Yb-doped fiber laser using a microfiber-based graphene saturable absorber. Opt. Express. 22(9), 10906-10913 (2014). https://doi.org/10.1364/OE.22.010906

21. Bao, Q., Loh, K.P.: Graphene photonics, plasmonics, and broadband optoelectronic devices. ACS NANO. 6, 3677-3694 (2012)

22. Geim, A.K., Novoselov, K.S.: The rise of graphene. Nat. Mater. 6, 183-191 (2007)

23. Kelleher, E.J.R., et al.: Nanosecond-pulse fiber lasers mode-locked with nanotubes. Appl. Phys. Lett. 95(11), 111108 (2009). https://doi.org/10.1 063/1.3207828

24. Lagatsky, A.A., et al:: 2 m solid-state laser mode-locked by single-layer graphene. Appl. Phys. Lett. 102(1), 013113 (2013). https://doi.org/10.1063/1.4 773990

25. Li, J., et al.: Black phosphorus: a two-dimension saturable absorption material for mid-infrared Q-switched and mode-locked fiber lasers. Sci. Rep. 6, 30361 (2016). https://doi.org/10.1038/srep30361

26. Li, P., Zhang, G., Zhang, H., Zhao, C., Chi, J., Zhao, Z., Yang, C., Hu, H., Yao, Y.: Q -switched mode-locked Nd:YVO4 laser by topological insulator Bi2Te3 saturable absorber. IEEE Photon. Technol. Lett. 26(19), 1912-1915 (2014). https://doi.org/10.1109//pt.2014.2341832

27. Li, X.H., Wang, Y.S., Zhao, W., Zhang, W., Yang, Z., Hu, X.H., Wang, H.S., Wang, X.L., Zhang, Y.N., Gong, Y.K., Li, C., Shen, D.Y.: All-normal dispersion, figureeight, tunable passively mode-locked fiber laser with an invisible and changeable intracavity bandpass filter. Laser Phys. 21(5), 940-944 (2011). https://doi.org/10.1134/s1054660×11090143

28. Peng, J., Zhan, L., Luo, S., Shen, Q.S.: Generation of Soliton molecules in a Normal-dispersion Fiber laser. IEEE Photon. Technol. Lett. 25(10), 948-951 (2013). https://doi.org/10.1109//pt.2013.2257720

29. Runge, A.F.J., Aguergaray, C., Provo, R., Erkintalo, M., Broderick, N.G.R.: Allnormal dispersion fiber lasers mode-locked with a nonlinear amplifying loop mirror. Opt. Fiber Technol. 20(6), 657-665 (2014). https://doi.org/10.101 6/j.yofte.2014.07.010

30. Scardaci, V., Sun, Z., Wang, F., Rozhin, A.G., Hasan, T., Hennrich, F., White, I.H., Milne, W.I., Ferrari, A.C.: Carbon nanotube polycarbonate composites for ultrafast lasers. Adv. Mater. 20(21), 4040-4043 (2008). https://doi.org/10.1 002/adma.200800935

31. Schwierz, F.: Graphene transistors. Nat. Nanotechnol. 5(7), 487-496 (Jul 2010). https://doi.org/10.1038/nnano.2010.89

32. Sotor, J., et al.: Passive synchronization of erbium and thulium doped fiber mode-locked lasers enhanced by common graphene saturable absorber Opt. Express. 22(5), 5536-5543 (2014). https://doi.org/10.1364/OE.22.005536

33. Sun, Z., Hasan, T., Ferrari, A.C.: Ultrafast lasers mode-locked by nanotubes and graphene. Phys. E: Low-dimensional Syst. Nanostructures. 44(6), 1082 1091 (2012). https://doi.org/10.1016/j.physe.2012.01.012

34. Wang, Y., Zhang, B., Yang, H., Hou, J., Su, X., Sun, Z., He, J.: Passively modelocked solid-state laser with absorption tunable graphene saturable absorber mirror. J. Lightwave Technol. 37(13), 2927-2931 (2019). https://doi. org/10.1109/jlt.2019.2907654

35. Wise, F.W., Chong, A., Renninger, W.H.: High-energy femtosecond fiber lasers based on pulse propagation at normal dispersion. Laser Photon. Rev. 2(1-2), 58-73 (2008). https://doi.org/10.1002//por.200710041

36. Woodward, R., Kelleher, E.: 2D saturable absorbers for fibre lasers. Appl. Sci. 5(4), 1440-1456 (2015). https://doi.org/10.3390/app5041440

37. $\mathrm{Wu}, \mathrm{H} .-\mathrm{Q} .$, Linghu, C.-Y., Lu, H.-M., Qian, H.: Graphene applications in electronic and optoelectronic devices and circuits. Chin. Phys. B. 22(9), 098106 (2013). https://doi.org/10.1088/1674-1056/22/9/098106

38. Xia, $H_{\text {., }}$ et al.: Ultrafast erbium-doped fiber laser mode-locked by a CVDgrown molybdenum disulfide (MoS2) saturable absorber. Opt. Express. 22(14), 17341-17348 (2014). https://doi.org/10.1364/OE.22.017341

39. Zhang, G., Wang, Y., Chen, Z., Jiao, Z.: Graphene oxide based reflective saturable absorber for Q-switched and mode-locked YVO4/Nd:YVO4/ WO4laser. J. Opt. 20(5), 055505 (2018). https://doi.org/10.1088/2040-8986/aa b7a6
40. Zhang, H., Tang, D.Y., Zhao, L.M., Bao, Q.L., Loh, K.P.: Large energy mode locking of an erbium-doped fiber laser with atomic layer graphene. Opt. Express. 17(19), 17630-17635 (2009). https://doi.org/10.1002/adfm.200901 007

41. Zhang, X., et al.: Saturable absorption in graphene at $800-\mathrm{nm}$ band. Optoelectronic Devices And Integration Iv. 8555, 855512 (2012). https://doi. org/10.1117/12.999624

42. Zhao, L., Li, D., Li, L., Wang, X., Geng, Y., Shen, D., Su, L.: Route to larger pulse energy in ultrafast fiber lasers. IEEE J. Selected Top. Quantum Electron. 24(3), 1-9 (2018). https://doi.org/10.1109/jstqe.2017.2771739

43. Zhong, Y., Cai, Z., Wu, D., Cheng, Y., Peng, J., Weng, J., Luo, Z., Xu, B., Xu, H.: Passively Q-switched red Pr3+-doped fiber laser with graphene-oxide saturable absorber. IEEE Photon. Technol. Lett. 28(16), 1755-1758 (2016). https://doi.org/10.1109/lpt.2016.2550859

44. Dzhibladze, M.I., Esiashvili, Z.G., TeplitskiT, E.S., Isaev, S.K., Sagaradze, V.R.: Mode locking in a fiber laser. IOP Sci. 13(2), 245-246 (1983)

45. Martinez, A., Sun, Z.: Nanotube and graphene saturable absorbers for fibre lasers. Nat. Photonics. 7(11), 842-845 (2013). https://doi.org/10.1038/ nphoton.2013.304

46. T. Hasan, Z. Sun, F. Wang, F. Bonaccorso, P. H. Tan, A. G. Rozhin, A. C. Ferrari, "Nanotubeâ "Polymer composites for ultrafast photonics," Adv. Mater., 21, 38â "39, 3874-3899, 2009, doi: https://doi.org/10.1002/adma.200901122,

47. Gerosa, R.M., Suarez, F.G., Vianna, P.G., Domingues, S.H., de Matos, C.J.S.: One-step deposition and in-situ reduction of graphene oxide in photonic crystal fiber for all-fiber laser mode locking. Opt. Laser Technol. 121, 105838 (2020). https://doi.org/10.1016/j.optlastec.2019.105838

48. Martinez, A., Fuse, K., Xu, B., Yamashita, S.: Optical deposition of graphene and carbon nanotubes in a fiber ferrule for passive modelocked lasing. Opt. Express. 18(22), 23054-23061 (2010). https://doi.org/10.1364/OE.18.023054

49. Yanagida, T., Watanabe, K., Okada, G., Kawaguchi, N.: Optical, scintillation and radiation tolerance properties of Pr-doped pyrosilicate crystals. Jpn J. Appl. Phys. 57(10), 106401 (2018). https://doi.org/10.7567/jjap.57.106401

50. Zhang, M., Kelleher, E.J.R., Pozharov, A.S., Obraztsova, E.D., Popov, S.V., Taylor, J.R.: Passive synchronization of all-fiber lasers through a common saturable absorber. Opt. Lett. 36(20), 3984-3986 (2011). https://doi.org/10.1364/OL.36. 003984

51. Ni, Z.H., Wang, H.M., Kasim, J., Fan, H.M., Yu, T., Wu, Y.H., Feng, Y.P., Shen, Z. $X$ : Graphene thickness determination using reflection and contrast spectroscopy. Am. Chem. Soc. 7, 2758-2763 (2007)

52. Bo, F., Yi, H., Xiaosheng, X., Hongwei, Z., Zhipei, S., Changxi, Y.: Broadband graphene saturable absorber for pulsed fiber lasers at 1, 1.5, and $2 \mu \mathrm{m}$. IEEE J. Selected Top. Quantum Electron. 20(5), 411-415 (2014). https://doi.org/1 $0.1109 /$ jstqe.2014.2302361

53. Bao, Q., Zhang, H., Wang, Y., Ni, Z., Yan, Y., Shen, Z.X., Loh, K.P., Tang, D.Y.: Atomic-layer graphene as a saturable absorber for ultrafast pulsed lasers. Adv. Funct. Mater. 19(19), 3077-3083 (2009). https://doi.org/10.1002/adfm.2 00901007

54. Dai, T., Liu, X., Lei, W., Zhang, J.: Passively Q-Switched Nd:YVO4 Laser Based on Silver-Plated Graphene Saturable Absorber. IEEE (2019)

55. Wang, Y.Y., et al.: Raman Studies of monolayer graphene: the substrate effect. Am. Chem. Soc. 12, 10637-10639 (2008)

56. Ni, Z.H., Wang, Y.y., Yu, T., Shen, Z.X., Wang, H.m., Wu, Y.H., Chen, W., Shen Wee, A.T: Raman studies of monolayer graphene: the substrate effect. J. Phys. Chem. C. 112, 10637-10639 (2008)

57. Zheng, Z., Zhao, C., Lu, S., Chen, Y., Li, Y., Zhang, H., Wen, S.: Microwave and optical saturable absorption in graphene. Opt. Express. 20(21), 23201-23214 (2012). https://doi.org/10.1364/OE.20.023201

58. Zhu, Y., et al.: Graphene and graphene oxide: synthesis, properties, and applications. Adv. Mater. 22(35), 3906-3924 (2010). https://doi.org/10.1002/a dma.201001068

59. Park, S., Ruoff, R.S.: Chemical methods for the production of graphenes. Nat. Nanotechnol. 4(4), 217-224 (Apr 2009). https://doi.org/10.1038/nnano.2009.58

60. Ghanbari, H., Shafikhani, M.A., Daryalaal, M.: Graphene nanosheets production using liquid-phase exfoliation of pre-milled graphite in dimethylformamide and structural defects evaluation. Ceram. Int. 45(16), 20051-20057 (2019). https://doi.org/10.1016/j.ceramint.2019.06.267

61. Chakrabarti, M.H., Manan, N.S.A., Brandon, N.P., Maher, R.C., Mjalli, F.S., AlNashef, I.M., Hajimolana, S.A., Hashim, M.A., Hussain, M.A., Nir, D.: One-pot electrochemical gram-scale synthesis of graphene using deep eutectic solvents and acetonitrile. Chem. Eng. J. 274, 213-223 (2015). https://doi. org/10.1016/j.cej.2015.03.083 
62. Hossain, S.T., Wang, R.: Electrochemical exfoliation of graphite: effect of temperature and hydrogen peroxide addition. Electrochim. Acta. 216, 253260 (2016). https://doi.org/10.1016/j.electacta.2016.09.022

63. Yu, P., Lowe, S.E., Simon, G.P., Zhong, Y.L.: Electrochemical exfoliation of graphite and production of functional graphene. Curr. Opin. Colloid Interface Sci. 20(5-6), 329-338 (2015). https://doi.org/10.1016/j.cocis.2015.10.007

64. Murdock, A.T., van Engers, C.D., Britton, J., Babenko, V., Meysami, S.S., Bishop, H., Crossley, A., Koos, A.A., Grobert, N.: Targeted removal of copper foil surface impurities for improved synthesis of CVD graphene. Carbon. 122 207-216 (2017). https://doi.org/10.1016/j.carbon.2017.06.075

65. Rodriguez, C.L.C., Kessler, F., Dubey, N., Rosa, V., Fechine, G.J.M.: CVD graphene transfer procedure to the surface of stainless steel for stem cell proliferation. Surf. Coat. Technol. 311, 10-18 (2017). https://doi.org/10.1016/j. surfcoat.2016.12.111

66. Gao, H., Xue, C., Hu, G., Zhu, K.: Production of graphene quantum dots by ultrasound-assisted exfoliation in supercritical $\mathrm{CO} 2 / \mathrm{H} 2 \mathrm{O}$ medium. Ultrason. Sonochem. 37, 120-127 (Jul 2017). https:/doi.org/10.1016/j.ultsonch.2017.01.001

67. Gao, H., Zhu, K., Hu, G., Xue, C.: Large-scale graphene production by ultrasound-assisted exfoliation of natural graphite in supercritical $\mathrm{CO} 2 / \mathrm{H} 2$ O medium. Chem. Eng. J. 308, 872-879 (2017). https://doi.org/10.1016/j.cej.2 016.09.132

68. Hadi, A., Karimi-Sabet, J., Moosavian, S.M.A., Ghorbanian, S.: Optimization of graphene production by exfoliation of graphite in supercritical ethanol: a response surface methodology approach. J. Supercrit. Fluids. 107, 92-105 (2016). https://doi.org/10.1016/j.supflu.2015.08.022

69. Song, N., Jia, J., Wang, W., Gao, Y., Zhao, Y., Chen, Y.: Green production of pristine graphene using fluid dynamic force in supercritical CO2. Chem. Eng. J. 298, 198-205 (2016). https://doi.org/10.1016/j.cej.2016.04.022

70. Chia, J.S.Y., Tan, M.T.T., SimKhiew, P., Chin, J.K., Lee, H., Bien, D.C.S., Teh, A.S. Siong, C.W.: Facile synthesis of few-layer graphene by mild solvent thermal exfoliation of highly oriented pyrolytic graphite. Chem. Eng. J. 231, 1-11 (2013). https://doi.org/10.1016/j.cej.2013.06.106

71. Keller, U.: Recent developments in compact ultrafast lasers. Nature. 424, 831-838 (2003)

72. Keller, U.: Semiconductor Saturable absorber mirrors (SESAM's) for femtosecond to nanosecond pulse generation in solid-state lasers. IEEE J. Selected Top. Quantum Electron. 2(3), 435-453 (1996). https://doi.org/10.11 09/2944.571743

73. Keller, U., Miller, D.A.B., Boyd, G.D., Chiu, T.H., Ferguson, J.F., Asom, M.T.: Solid-state low-loss intracavity saturable absorber for Nd:YLF lasers: an antiresonant semiconductor Fabry-Perot saturable absorber. Opt. Lett. 17(7), 505-507 (1992). https://doi.org/10.1364/OL.17.000505

74. Zhu, X., Chen, S.: Study of a graphene saturable absorber film fabricated by the optical deposition method. IEEE Photon. J. 11(6), 1-9 (2019). https://doi. org/10.1109/jphot.2019.2948940

75. Yan, Z., Li, T., Zhao, J., Zhao, S., Yang, K., Li, G., Li, D., Zhang, S., Li, J.: Tungsten ditelluride for a nanosecond Ho,Pr:LiLuF4 laser at $2.95 \mu \mathrm{m}$. Laser Phys. Lett. 15(4), 045801 (2018). https://doi.org/10.1088/1612-202X/aaa94b

76. Set, S.Y., Yaguchi, H., Tanaka, Y., Jablonski, M.: Ultrafast Fiber pulsed lasers incorporating carbon nanotubes. IEEE J. Selected Top. Quantum Electron. 10(1), 137-146 (2004). https://doi.org/10.1109/jstqe.2003.822912

77. Kajikawa, S., Yoshida, M., Ishii, O., Yamazaki, M., Fujimoto, Y.: Visible Qswitched pulse laser oscillation in Pr-doped double-clad structured waterproof fluoride glass fiber with graphene. Opt. Commun. 424, 13-16 (2018). https://doi.org/10.1016/j.optcom.2018.04.024

78. Sotor, J., Sobon, G., Abramski, K.M.: Er-doped fibre laser mode-locked by mechanically exfoliated graphene saturable absorber. Opto-Electron. 20(4), 362-366 (2012). https://doi.org/10.2478/s11772-012-0043-9

79. Ahmad, H., Soltani, S., Thambiratnam, K.: Q-switched erbium-doped fiber laser with molybdenum disulfide (MoS2) nanoparticles on D-shaped fiber as saturable absorber. J. Nonlin. Opt. Phys. Mater. 28(03), 1950026 (2019). https://doi.org/10.1142/s0218863519500267

80. Chen, T., Liao, C., Wang, D.N., Wang, Y.: Passively mode-locked fiber laser by using monolayer chemical vapor deposition of graphene on D-shaped fiber. Appl. Opt. 53(13), 2828-2832 (2014). https://doi.org/10.1364/AO.53.002828

81. Zapata, J.D., Steinberg, D., Saito, L.A., de Oliveira, R.E., Cardenas, A.M., de Souza, E.A.: Efficient graphene saturable absorbers on D-shaped optical fiber for ultrashort pulse generation. Sci. Rep. 6, 20644 (2016). https://doi.org/10.1 038/srep20644

82. Zapata, J.D., Steinberg, D., Saito, L.A.M., de Oliveira, R.E.P., Cárdenas, A.M., de Souza, E.A.T.: Efficient graphene saturable absorbers on D-shaped optical fiber for ultrashort pulse generation. Sci. Rep. 6(1), (2016). https://doi.org/1 0.1038/srep20644

83. Aiub, E.J., Steinberg, D., Thoroh de Souza, E.A., Saito, L.A.M.: 200-fs modelocked Erbium-doped fiber laser by using mechanically exfoliated MoS< sub $>2</$ sub $>$ saturable absorber onto D-shaped optical fiber. Opt. Express. 25(9), 10546-10552 (2017). https://doi.org/10.1364/OE.25.010546

84. Gerosa, R.M., Steinberg, D., Pellicer, F.N., Domingues, S.H., Souza, E.A.T.d., Saito, L.A.M.: 300-fs mode-locked Erbium doped fiber laser using evanescent field interaction through graphene oxide saturable absorber in D-shaped fibers. In: Latin America Optics and Photonics Conference (2016)

85. Steinberg, D., et al.: Graphene oxide and reduced graphene oxide as saturable absorbers onto D-shaped fibers for sub 200-fs EDFL mode-locking. Opt. Mater. Express. 8(1), 144 (2017). https://doi.org/10.1364/ome.8.000144

86. Yang, H.R.: Switchable dual-wavelength fiber laser mode-locked by monolayer graphene on D-shaped fiber. J. Mod. Opt. 62(17), 1363-1367 (2015). https://doi.org/10.1080/09500340.2015.1039616

87. Huang, Q., Zou, C., Wang, T., Al Araimi, M., Rozhin, A., Mou, C.: Influence of average cavity dispersion and spectral bandwidth on passively harmonic mode locked L-band Er-doped Fiber laser. IEEE J. Selected Top. Quantum Electron. 25(4), 1-8 (2019). https://doi.org/10.1109/jstqe.2019.2924869

88. Ahmad, H., Reduan, S.A., Yusoff, N., Ismail, M.F., Aidit, S.N.: Mode-locked pulse generation in erbium-doped fiber laser by evanescent field interaction with reduced graphene oxide-titanium dioxide nanohybrid. Opt. Laser Technol. 118, 93-101 (2019). https://doi.org/10.1016/j.optlastec.2019.05.015

89. Ahmad, H., Soltani, S., Thambiratnam, K., Yasin, M., Tiu, Z.C.: Mode-locking in Er-doped fiber laser with reduced graphene oxide on a side-polished fiber as saturable absorber. Opt. Fiber Technol. 50, 177-182 (2019). https://doi. org/10.1016/j.yofte.2019.03.023

90. Salim, M.A.M., Ismail, M.A., Razak, M.Z.A., Azzuhri, S.R.: Generation of Ultrafast Erbium-Doped Fiber Laser (EDFL) utilizing Graphene Thin Film. J. Phys.: Conf. Ser. 1484, 012026 (2020). https://doi.org/10.1088/1742-6596/1484/1/012026

91. Chen, Z.-D., et al.: Reduced graphene oxide as saturable absorbers for erbium-doped passively mode-locked fiber laser. Chin. Phys. B. 27(8), 084206 (2018). https://doi.org/10.1088/1674-1056/27/8/084206

92. Wang, P., Xu, X., Guo, Z., Jin, X., Shi, G.: $926 \mathrm{~nm}$ Yb-doped fiber femtosecond laser system for two-photon microscopy. Appl. Phys. Express. 12(3), 032008 (2019). https://doi.org/10.7567/1882-0786/aafe8a

93. Haris, H., Harun, S.W., Jusoh, Z.: Generation of bound state of solitons pulses with graphene in erbium-doped fiber laser cavity. J. Phys. Conf. Ser. 1151, 012017 (2019). https://doi.org/10.1088/1742-6596/1151/1/012017

94. Pawliszewska, M., Martynkien, T., Przewloka, A., Sotor, J.: Dispersion-managed Ho-doped fiber laser mode-locked with a graphene saturable absorber. Opt. Lett. 43(1), 38-41 (2018). https://doi.org/10.1364/OL.43.000038

95. Wang, C., et al.: Few-layer bismuthene for femtosecond soliton molecules generation in Er-doped fiber laser. Nanotechnology. 30(2), 025204 (2019). https://doi.org/10.1088/1361-6528/aae8c1

96. Steinberg, D., Zapata, J.D., Thoroh de Souza, E.A., Saito, L.A.M.: Mechanically exfoliated graphite onto D-shaped optical Fiber for femtosecond modelocked erbium-doped fiber laser. J. Lightwave Technol. 36(10), 1868-1874 (2018). https://doi.org/10.1109/jt.2018.2793764

97. Uehara, H., Tokita, S., Kawanaka, J., Konishi, D., Murakami, M., Yasuhara, R.: A passively Q-switched compact Er:Lu2O3 ceramics laser at $2.8 \mu \mathrm{m}$ with a graphene saturable absorber. Appl. Phys. Express. 12(2), 022002 (2019). https://doi.org/10.7567/1882-0786/aaf994

98. Ahmad, H., Albaqawi, H.S., Yusoff, N., Reduan, S.A., Yi, C.W.: Reduced Graphene Oxide-Silver Nanoparticles for Optical Pulse Generation in Ytterbium- and Erbium-Doped Fiber Lasers. Sci. Rep. 10(1), 9408 (2020). https://doi.org/10.1038/s41598-020-66253-w

99. Kim, H., Cho, J., Jang, S.-Y., Song, Y.-W.: Deformation-immunized optical deposition of graphene for ultrafast pulsed lasers. Appl. Phys. Lett. 98(2), 021104 (2011). https://doi.org/10.1063/1.3536502

100. Li, T.-C., Han, C.-F., Hsieh, K.-C., Lin, J.-F.: Effects of thin titanium and graphene depositions and annealing temperature on electrical, optical, and mechanical properties of IGZO/Ti/graphene/PI specimen. Ceram. Int. 44(6), 6573-6583 (2018). https://doi.org/10.1016/j.ceramint.2018.01.060

101. Saeed, M., Alshammari, Y., Majeed, S.A., Al-Nasrallah, E.: Chemical vapour deposition of graphene-synthesis, characterisation, and applications: a review. Molecules. 25(17), (2020). https:/doi.org/10.3390/molecules25173856

102. Yu, L., Yin, Y., Shi, Y., Dai, D., He, S.: Thermally tunable silicon photonic microdisk resonator with transparent graphene nanoheaters. Optica. 3(2), (2016). https://doi.org/10.1364/optica.3.000159 
103. Kawase, H., Uehara, H., Chen, H., Yasuhara, R.: Passively Q-switched 2.9 $\mathrm{m}$ Er:YAP single crystal laser using graphene saturable absorber. Appl. Phys. Express. 12(10), 102006 (2019). https://doi. org/10.7567/1882-0786/ab3e61

104. Zhang, R., Wang, J., Liao, M., Li, X., Kuan, P.W., Liu, Y., Zhou, Y., Gao, W.: Tunable Q-switched fiber laser based on a graphene saturable absorber without additional tuning element. IEEE Photon. J. 11(1), 1-10 (2019). https://doi.org/10.1109/jphot.2019.2892646

105. Sobon, G., Sotor, J., Pasternak, I., Grodecki, K., Paletko, P., Strupinski, W., Jankiewicz, Z., Abramski, K.M.: Er-doped fiber laser mode-locked by CVDgraphene saturable absorber. J. Lightwave Technol. 30(17), 2770-2775 (2012). https://doi.org/10.1109/jtt.2012.2207092

106. Sotor, J., Sobon, G., Krzempek, K., Abramski, K.M.: Fundamental and harmonic mode-locking in erbium-doped fiber laser based on graphene saturable absorber. Opt. Commun. 285(13-14), 3174-3178 (2012). https:// doi.org/10.1016/j.optcom.2012.03.002

107. Zhu, G., Zhu, X., Wang, F., Xu, S., Li, Y., Guo, X., Balakrishnan, K., Norwood, R.A., Peyghambarian, N.: Graphene mode-locked Fiber laser at $2.8 \mu \mathrm{m}$. IEEE Photon. Technol. Lett. 28(1), 7-10 (2016). https://doi.org/10.1109/lpt.2015.2478836

108. Cao, W.J., Wang, H.Y., Luo, A.P., Luo, Z.C., Xu, W.C.: Graphene-based, 50 nm wide-band tunable passively Q-switched fiber laser. Laser Phys. Lett. 9(1), 54-58 (2012). https://doi.org/10.1002/lapl.201110085

109. Luo, Z., Zhou, M., Wu, D., Ye, C., Weng, J., Dong, J., Xu, H., Cai, Z., Chen, L.: Graphene-induced nonlinear four-wave-mixing and its application to multiwavelength Q-switched rare-earth-doped Fiber lasers. J. Lightwave Technol. 29(18), 2732-2739 (2011). https://doi.org/10.1109/jlt.2011.2164238

110. Zhang, H., Bao, Q., Tang, D., Zhao, L., Loh, K.: Large energy soliton erbiumdoped fiber laser with a graphene-polymer composite mode locker. Appl. Phys. Lett. 95(14), 141103 (2009). https://doi.org/10.1063/1.3244206

111. Liu, X.M., et al.: Graphene-clad microfibre saturable absorber for ultrafast fibre lasers. Sci. Rep. 6, 26024 (2016). https://doi.org/10.1038/srep26024

112. Lv, R.-d., et al.: Carboxyl graphene oxide solution saturable absorber for femtosecond mode-locked erbium-doped fiber laser. Chin. Phys. B. 27(11), 114214 (2018). https://doi.org/10.1088/1674-1056/27/11/114214

113. Wang, Z., Zhu, S.E., Chen, Y., Wu, M., Zhao, C., Zhang, H., Janssen, G.C.A.M., Wen, S.: Multilayer graphene for Q-switched mode-locking operation in an erbium-doped fiber laser. Opt. Commun. 300, 17-21 (2013). https://doi. org/10.1016/j.optcom.2013.03.010

114. Xu, J., Wu, S., Liu, J., Wang, Q., Yang, Q.-H., Wang, P.: Nanosecond-pulsed erbium-doped fiber lasers with graphene saturable absorber. Opt. Commun. 285(21-22), 4466-4469 (2012). https://doi.org/10.1016/j.optcom.2012.07.012

115. Fu, B., Gui, L., Zhang, W., Xiao, X., Zhu, H., Yang, C.: Passive harmonic mode locking in erbium-doped fiber laser with graphene saturable absorber. Opt. Commun. 286, 304-308 (2013). https://doi.org/10.1016/j.optcom.2012.09.026

116. Sobon, G., Sotor, J., Abramski, K.M.: Passive harmonic mode-locking in Erdoped fiber laser based on graphene saturable absorber with repetition rates scalable to $2.22 \mathrm{GHz}$. Appl. Phys. Lett. 100(16), 161109 (2012). https:// doi.org/10.1063/1.4704913

117. Peng, J., Zhan, L., Luo, S., Shen, Q.: Passive harmonic mode-locking of dissipative solitons in a normal-dispersion Er-doped fiber laser. J. Lightwave Technol. 31(16), 2709-2714 (2013). https://doi.org/10.1109/jtt.2013.2271773

118. Sobon, G., Sotor, J., Pasternak, I., Krajewska, A., Strupinski, W., Abramski, K.M.: Multilayer graphene-based saturable absorbers with scalable modulation depth for mode-locked Er- and Tm-doped fiber lasers. Opt. Mater. Express. 5(12), 2884 (2015). https://doi.org/10.1364/ome.5.002884

119. Boguslawski, J., et al.: Graphene oxide paper as a saturable absorber for Erand Tm-doped fiber lasers. Photon. Res. 3(4), 119 (2015). https://doi.org/1 0.1364/prj.3.000119

120. Chen, H.R., Tsai, C.Y., Cheng, H.M., Lin, K.H., Hsieh, W.F.: Passive mode locking of ytterbium- and erbium-doped all-fiber lasers using graphene oxide saturable absorbers. Opt. Express. 22(11), 12880-12889 (2014). https://doi. org/10.1364/OE.22.012880

121. Chen, H.-R., Tsai, C.-Y., Chang, C.-Y., Lin, K.-H., Chang, C.-S., Hsieh, W.-F.: Investigation of Graphene dispersion from Kelly sideband in stable mode-locked erbium-doped Fiber laser by few-layer graphene saturable absorbers. J. Lightwave Technol. 33(21), 4406-4412 (2015). https://doi.org/10.1109/jt.2015.2471100

122. Rosa, H.G., Steinberg, D., Zapata, J.D., Saito, L.A.M., Cardenas, A.M., Gomes, J. C.V., Thoroh de Souza, E.A.: Raman mapping characterization of all-Fiber CVD monolayer graphene saturable absorbers for erbium-doped fiber laser mode locking. J. Lightwave Technol. 33(19), 4118-4123 (2015). https://doi. org/10.1109/jlt.2015.2467173
123. Rosa, H.G., et al.: Controlled stacking of graphene monolayer saturable absorbers for ultrashort pulse generation in erbium-doped fiber lasers. Opt. Mater. Express. 7(7), 2528 (2017). https://doi.org/10.1364/ome.7.002528

124. Sobon, G., Sotor, J., Jagiello, J., Kozinski, R., Zdrojek, M., Holdynski, M., Paletko, P., Boguslawski, J., Lipinska, L., Abramski, K.M.: Graphene oxide vs. reduced graphene oxide as saturable absorbers for Er-doped passively mode-locked fiber laser. Opt. Express. 20(17), 19463-19473 (2012). https://doi.org/10.1364/OE.20.019463

125. Wang, Z., Mu, H., Yuan, J., Zhao, C., Bao, Q., Zhang, H.: Graphene-Bi2Te3 Heterostructure as broadband Saturable absorber for ultra-short pulse generation in Er-doped and Yb-doped Fiber lasers. IEEE J. Selected Top. Quantum Electron. 23(1), 195-199 (2017). https://doi.org/10.1109/jstqe.2016.2514784

126. Sobon, G., et al.: Linearly polarized, Q-switched Er-doped fiber laser based on reduced graphene oxide saturable absorber. Appl. Phys. Lett. 101(24), 241106 (2012). https://doi.org/10.1063/1.4770373

127. Rosdin, R.Z.R.R.R.R.Z.R.R., Ahmad, F.A.F., Ali, N.M.A.N.M., Harun, S.W.H.S.W., Arof, H.A.H.: Q-switched Er-doped fiber laser with low pumping threshold using graphene saturable absorber. Chin. Opt. Lett. 12(9), 091404-091408 (2014). https://doi.org/10.3788/col201412.091404

128. Wang, Z.T., Chen, Y., Zhao, C.J., Zhang, H., Wen, S.C.: Switchable dualwavelength synchronously Q-switched erbium-doped Fiber laser based on graphene saturable absorber. IEEE Photon. J. 4(3), 869-876 (2012). https:// doi.org/10.1109/jphot.2012.2199102

129. Zhao, J.-Q., et al.: Graphene-oxide-based Q-switched fiber laser with stable five-wavelength operation. Chin. Phys. Lett. 29(11), 114206 (2012). https:// doi.org/10.1088/0256-307x/29/11/114206

130. Z. Cheng, S. Wu, H. Shi, J. Xu, Q.-H. Yang, and P. Wang, "Dissipative soliton resonance in an all-normal-dispersion graphene oxide mode-locked $\mathrm{Yb}$ doped fiber laser" Tech. Dig., 2013

131. Huang, S., Wang, Y., Peiguang, Y., Zhang, G., Zhao, J., Li, H., Lin, R., Cao, G., Duan, J.:.: Observation of multipulse bunches in a graphene oxide passively mode-locked ytterbium-doped fiber laser with all-normal dispersion. Appl. Phys. B. 116(4), 939-946 (2014). https://doi.org/10.1007/s00340-014-5780-7

132. Luo, Z., Huang, Y., Wang, J., Cheng, H., Cai, Z., Ye, C.: Multiwavelength dissipative-soliton generation in Yb-fiber laser using graphene-deposited Fiber-taper. IEEE Photon. Technol. Lett. 24(17), 1539-1542 (2012). https://doi. org/10.1109//pt.2012.2208100

133. Li, H., Wang, Y., Yan, P., Cao, G., Zhao, J., Zhang, G., Huang, S., Lin, R.: Passively harmonic mode locking in ytterbium-doped fiber laser with graphene oxide saturable absorber. Opt. Eng. 52, 126102 (2013). https://doi. org/10.1117/1.OE.52.12.126102

134. Huang, S.S., et al.: Soliton rains in a graphene-oxide passively mode-locked ytterbium-doped fiber laser with all-normal dispersion. Laser Phys. Lett. 11(2), 025102 (2014). https://doi.org/10.1088/1612-2011/11/2/025102

135. Huaiqin, L., et al.: Tunable and switchable dual-wavelength dissipative soliton operation of a weak-birefringence all-Normal-dispersion Yb-doped Fiber laser. IEEE Photon. J. 5(5), 1501807-1501807 (2013). https://doi.org/1 0.1109/jphot.2013.2281977

136. Cheng, Z., Li, H., Shi, H., Ren, J., Yang, Q.H., Wang, P.: Dissipative soliton resonance and reverse saturable absorption in graphene oxide modelocked all-normal-dispersion Yb-doped fiber laser. Opt. Express. 23(6), 70007006 (2015). https://doi.org/10.1364/OE.23.007000

137. Hou, L., et al.: Femtosecond ytterbium-doped fiber laser mode-locked by carboxyl-functionalized graphene oxide saturable absorber. Appl. Phys. Express. 11(1), 012702 (2018). https://doi.org/10.7567/apex.11.012702

138. Huang, S., Wang, Y., Yan, P., Zhao, J., Li, H., Lin, R.: Tunable and switchable multi-wavelength dissipative soliton generation in a graphene oxide modelocked Yb-doped fiber laser. Opt. Express. 22(10), 11417-11426 (2014). https://doi.org/10.1364/OE.22.011417

139. Huang, S.S., et al.: High order harmonic mode-locking in an all-normal-dispersion Yb-doped fiber laser with a graphene oxide saturable absorber. Laser Phys. 24(1), 015001 (2014). https://doi.org/10.1088/1054-660x/24/1/015001

140. Loiko, P.A., et al.: Passive Q-switching of Yb bulk lasers by a graphene saturable absorber. Appl. Phys. B. 122(4), (2016). https://doi.org/10.1007/ s00340-016-6384-1

141. Liu, J., Wu, S., Yang, Q.-h., Wang, P.: Mode-locked and Q-switched Yb-doped fiber lasers with graphene saturable absorber. Optoelectronic Devices And Integration IV. 8192, 819244 (2011). https://doi.org/10.1117/12.901098

142. Fan, L., Dong, Z., Guoyu, H., Guo, J., Xu, C., Li, K., Tian, J., Song, Y.: Influence of few-layer WS2 and mono-layer WS2 on passively Q-switched ytterbiumdoped fibre lasers. Laser Phys. 29(7), 075104 (2019). https://doi.org/10.1 088/1555-6611/ab20c2 
143. Yusoff, R.A.M., Jafry, A.A.A., Kasim, N., Munajat, Y., Harun, S.W., Halim, N.A.H.: Q-switched ytterbium-doped fiber laser using graphene oxide as passive saturable absorber. J. Phys. Conf. Ser. 1371, 012004 (2019). https://doi.org/1 0.1088/1742-6596/1371/1/012004

144. Zhao, F., Wang, H., Zhang, T., Wang, Y., Hu, X., Sun, C., Zhang, W.: Passively Q-switched all-fiber Yb-doped lasers based on nonlinear multimode interferencet. J. Russ. Laser Res. 40(1), 87-93 (2019). https://doi.org/10.1007/ s10946-019-09774-8

145. Ren, Y., Feng, M., Ren, A., Zhang, K., Yang, J., Sun, G., Wang, T., Li, Z., Li, Y., Liu, Z., Song, F.: Dynamics of the passive synchronisation of erbium- and ytterbium-doped fibre Q-switched lasers with a common graphene saturable absorber. Laser Phys. 29(8), 085101 (2019). https://doi.org/10.1 088/1555-6611/ab23ec

146. Liu, J., Wang, Y.G., Qu, Z.S., Zheng, L.H., Su, L.B., Xu, J.: Graphene oxide absorber for $2 \mu \mathrm{m}$ passive mode-locking tm:YAlO3 laser. Laser Phys. Lett. 9(1), 15-19 (2012). https://doi.org/10.1002/lapl.201110087

147. Zhang, E.J.R.K.M., Torrisi, F., Sun, Z., Hasan, T., Popa, D., Wang, F., Ferrari, A.C., Popov, S.V., Taylor, J.R.: Tm-doped fiber laser mode-locked by graphenepolymer composite. Opt. Soc. Am. 20, 25077-25084 (2012)

148. Sobon, G., Sotor, J., Pasternak, I., Krajewska, A., Strupinski, W., Abramski, K.M.: All-polarization maintaining, graphene-based femtosecond Tm-doped allfiber laser. Opt. Express. 23(7), 9339-9346 (2015). https://doi.org/10.1364/ OE.23.009339

149. Zhang, M., Kelleher, E.J.R., Torrisi, F., Sun, Z., Hasan, T., Popa, D., Wang, F., Ferrari, A.C., Popov, S.V., Taylor, J.R.: Tm-doped fiber laser mode-locked by graphene-polymer composite. Opt. Express. 20(22), 25077-25084 (2012). https://doi.org/10.1364/OE.20.025077

150. Yan, Z., et al.: Tunable and switchable dual-wavelength Tm-doped modelocked fiber laser by nonlinear polarization evolution. Opt. Express. 23(4), 4369-4376 (2015). https://doi.org/10.1364/OE.23.004369

151. Wang, J., et al.: 152 fs nanotube-mode-locked thulium-doped all-fiber laser. Sci Rep. 6, 28885 (2016). https://doi.org/10.1038/srep28885

152. Liu, J., Xia, K., Zhang, W., Zhu, J., Yan, B., Yang, P., Dai, S., Nie, Q.: Tm-doped all-fiber structured femtosecond laser mode-locked by a novel Chem-Te saturable absorber. Infrared Phys. Technol. 108, 103343 (2020). https://doi. org/10.1016/j.infrared.2020.103343

153. Ahmad, H., Reduan, S.A., Ooi, S.I., Ismail, M.A.: Mechanically exfoliated In2Se3 as a saturable absorber for mode-locking a thulium-doped fluoride fiber laser operating in S-band. Appl Opt. 57(24), 6937-6942 (2018). https://doi. org/10.1364/AO.57.006937

154. Dou, Z., Zhang, B., He, X., Xu, Z., Hou, J.: High-power and large-energy dissipative soliton resonance in a compact tm-doped all-fiber laser. IEEE Photon. Technol. Lett. 31(5), 381-384 (2019). https://doi.org/10.1109/lpt.2019.2895906

155. Sotor, J., et al.: All-polarization-maintaining, stretched-pulse Tm-doped fiber laser, mode-locked by a graphene saturable absorber. Opt. Lett. 42(8), 1592-1595 (2017). https://doi.org/10.1364/OL.42.001592

156. Zhang, Q., Jiang, X., Zhang, M., Jin, X., Zhang, H., Zheng, Z.: Wideband saturable absorption in metal-organic frameworks (MOFs) for mode-locking Er- and Tm-doped fiber lasers. Nanoscale. 12(7), 4586-4590 (2020). https:// doi.org/10.1039/c9nr09330c

157. Xie, G.Q., et al.: Graphene saturable absorber for Q-switching and mode locking at $2 \mu \mathrm{m}$ wavelength. Opt. Mater. Express. 2, 879-883 (2012)

158. Ahmad, H., Samion, M.Z., Sharbirin, A.S., Ismail, M.F.: Dual-wavelength, passively Q-switched thulium-doped fiber laser with N-doped graphene saturable absorber. Optik. 149, 391-397 (2017). https://doi.org/10.1016/j. ijleo.2017.09.054

159. Luo, Z., Li, Y., Huang, Y., Zhong, M., Wan, X.: Graphene mode-locked and Qswitched 2- $\mu \mathrm{m} \mathrm{Tm} / \mathrm{Ho}$ codoped fiber lasers using 1212-nm high-efficient pumping. Opt. Eng 55(8), 081310(1-6) (2016). https://doi.org/10.1117/1.0E.55.8.081310

160. Ahmad, H., Reduan, S.A., Aidit, S.N., Yusoff, N., Maah, M.J., Ismail, M.F., Tiu, Z C.: Ternary MoWSe2 alloy saturable absorber for passively Q-switched Yb-, Er- and Tm-doped fiber laser. Opt. Commun. 437, 355-362 (2019). https:// doi.org/10.1016/j.optcom.2019.01.009

161. Ahmad, H., Samion, M.Z., Sharbirin, A.S., Norizan, S.F., Aidit, S.N., Ismail, M.F. Graphene-PVA saturable absorber for generation of a wavelength-tunable passively Q-switched thulium-doped fiber laser in 2.0 $\mathrm{mm}$. Laser Phys. 28(5), 055105 (2018). https://doi.org/10.1088/1555-6611/aab2cc

162. Wang, Q., Chen, T., Zhang, B., Li, M., Lu, Y., Chen, K.P.: All-fiber passively mode-locked thulium-doped fiber ring laser using optically deposited graphene saturable absorbers. Appl. Phys. Lett. 102(13), 131117 (2013). https://doi.org/10.1063/1.4800036
163. Sotor, J., et al.: All-fiber Ho-doped mode-locked oscillator based on a graphene saturable absorber. Opt. Lett. 41(11), 2592-2595 (2016). https:// doi.org/10.1364/OL.41.002592

164. Liu, S., et al.: Graphene Q-switched Ho (3+)-doped ZBLAN fiber laser at 1190 nm. Opt. Lett. 40(2), 147-150 (2015). https://doi.org/10.1364/OL.40.000147

165. Tengfei Dai, X.L., Lei, W., Chang, J.: Passively Q-Switched Nd:YVO 4 Laser Based on Silver-Plated Graphene Saturable Absorber. IEEE (2019)

166. Zhao, X., et al.: Picometer-Resolution, Dual-Comb Spectroscopy Based on a Dual-Wavelength Mode-Locked Fiber Laser. CLEO (2016)

167. Hu, G., Li, T., Pan, Y., Zhao, X., Zhang, M., Zheng, Z.: Asynchronous and Synchronous Dual-Wavelength Pulse Generation in a Non-zero-Dispersion Fiber Laser. CLEO (2017)

168. Chen, J., et al.: Self-Starting, Turn-Key Dual-Comb Mode-Locked Fiber Laser with a Few-Mode Fiber Filter. CLEO (2017)

169. Hu, G., et al.: Real-Time Absolute Frequency Measurement of ContinuousWave Terahertz Radiation Using a Free-Running, Dual-Wavelength, DualComb Mode-Locked Fiber Laser. CLEO (2016)

170. Zhao, X., Zheng, Z., Liu, Y., Hu, G., Liu, J.: "Dual-wavelength, bidirectional single-wall carbon nanotube mode-locked fiber laser," (in English). IEEE Photon. Technol. Lett. 26(17), 1722-1725 (Sep 2014). https://doi.org/10.11 09/lpt.2014.2332000

171. Liu, L., Zheng, Z., Zhao, X., Sun, S., Zhu, J.: Dual-wavelength passively qswitched erbium fiber laser based on a swnt absorber. FiO/LS Tech. Dig. (2012). https://doi.org/10.1364/FIO.2012.FM3G.6

172. Hu, G., Zhang, M.: Dual-Wavelength Passively Q-Switched Yb-Doped Fiber Laser Based on WS 2 Saturable Absorber and Intracavity Polarization. CLEO (2016)

173. Liu, L., et al.: "Dual-wavelength passively Q-switched Erbium doped fiber laser based on an SWNT saturable absorber," (in English). Opt. Commun. 294, 267-270 (2013). https://doi.org/10.1016/j.optcom.2012.11. 094

174. Hu, G., et al.: Measurement of absolute frequency of continuous-wave terahertz radiation in real time using a free-running, dual-wavelength mode-locked, erbium-doped fibre laser. Sci. Rep. 7, 42082 (2017). https://doi. org/10.1038/srep42082

175. Liu, L., Zhao, X., Zheng, Z., Wang, Q.: Fast, long-scan-range pump-probe measurement using a dual-wavelength mode-locked fiber laser. FiO/LS Tech. Dig. (2012). https://doi.org/10.1364/FIO.2012.FW2A.1

176. Zhao, X., Gong, Z., Liu, Y., Yang, Y., Hu, G., Zheng, Z.: Coherent dual-comb mode-locked fiber laser based on a birefringent ring cavity. Front. Optics/ Laser Sci. (2015). https://doi.org/10.1364/FIO.2015.FW3C.3

177. Chen, J., et al.: Low-power consumption dual-comb spectroscopy based on a battery-powered, free-running dual-comb laser system. Front. Opt. (2017). https://doi.org/10.1364/FIO.2017.JTu3A.17

178. Zhao, X., Zheng, Z., Liu, Y., Guan, J., Liu, L., Sun, Y.: High-resolution absolute distance measurement using a dual-wavelength, dual-comb, femtosecond fiber laser. CLEO Tech. Dig. (2012). https://doi.org/10.1364/CLEO_SI.2012.CM2

179. Zheng, Z., Zhao, X.: High-Resolution, Dual-Comb Asynchronous Sampling Enabled by Dual-Wavelength Ultrafast Fiber Lasers and its Applications. In: Conference on Lasers and Electro-Optics Pacific Rim (CLEO-PR) (2013)

180. Chen, J., et al.: Dual-wavelength, dual-comb fiber laser based on a nearlyadiabatic fiber-taper filter. Opt. Soc. Am. (2016). https://doi.org/10.1364/FIO.2 016.JTh2A.112

181. Hu, G.: Multiwavelength, subpicosecond pulse generation from a SWNT-SA mode-locked ring birefringent fiber laser. Nonlin. Opt. Fibers. (2015)

182. Liu, Y., et al.: Multi-wavelength dissipative soliton, single-wall carbon nanotube mode-locked fiber laser. FIO/ LS Tech. Dig. (2011)

183. Zhao, X., et al:: Switchable, dual-wavelength passively mode-locked ultrafast fiber laser based on a single-wall carbon nanotube modelocker and intracavity loss tuning. Opt. Soc. Am. 19, 11681173 (2011)

184. Hu, G., Pan, Y., Wang, R., Zhao, X., Zhang, M., Zheng, Z.: Synchronous dualwavelength pulse generation in an er-doped fiber laser with near-zero dispersion. Front. Optics/Laser Sci. (2016). https://doi.org/10.1364/FIO.2016. JW4A.31

185. Hu, G., et al.: Terahertz Dual-Comb Spectroscopy with a Free-Running, DualWavelength-Comb Fiber Laser. CLEO (2017) 
186. Zhao, X: Switchable, dual-wavelength passively mode-locked ultrafast fiber laser based on a single-wall carbon nanotube modelocker and intracavity loss tuning. Opt. Soc. Am. (2011). https://doi.org/10.1364/OE.19.001168

187. Zhao, X., Zheng, Z., Liu, L., Wang, Q., Chen, H., Liu, J.: Fast, long-scan-range pump-probe measurement based on asynchronous sampling using a dualwavelength mode-locked fiber laser. Opt. Soc. Am. (2012). https://doi.org/1 0.1364/OE.20.025584

\section{Publisher's Note}

Springer Nature remains neutral with regard to jurisdictional claims in published maps and institutional affiliations.

Submit your manuscript to a SpringerOpen ${ }^{\circ}$ journal and benefit from:

- Convenient online submission

Rigorous peer review

- Open access: articles freely available online

High visibility within the field

- Retaining the copyright to your article

Submit your next manuscript at $\boldsymbol{\sim}$ springeropen.com 